\title{
A biomechanical analysis of the skull and adductor chamber muscles in the Late Cretaceous Plesiosaur Libonectes
}

\author{
Ricardo Araújo and Michael J. Polcyn
}

\begin{abstract}
Plesiosaurs were a diverse clade of marine reptiles that spanned nearly threequarters of the Mesozoic (earliest Jurassic to latest Cretaceous). They exhibit variation in head and neck morphology that presumably relates to functional differences in feeding habits. However, from a biomechanical standpoint, these marine creatures have a cranial organization shared with few reptile clades: the neodiapsid condition. Nevertheless, basic structural features in some derived clades, such as elasmosaurids, remain poorly understood, namely the presence of large supratemporal fenestrae, tall temporal bars, and high parietal crests. These features present biomechanical compromises with paleobiological implications for feeding habits. Here we test specific hypotheses regarding skull structure and mechanics in the elasmosaurid plesiosaur Libonectes morgani from the Late Cretaceous of Texas (USA). Using finite element analysis and loadings based on a detailed reconstruction of adductor chamber musculature, we provide estimates of stress and strain distributions for the Libonectes skull. We also digitally morphed different anatomical variants of the Libonectes skull, in order to assess the role of those traits in skull's mechanical performance (e.g., height of the temporal bar). Our results show that a larger physiological cross-section of the adductor muscles is achieved by an enlarged supratemporal fenestra which although it reduces mechanical performance of the skull, it is offset by increased strength of a taller parietal crest and temporal bar, given the loading is largely symmetrical, the lateral components are offsetting yielding a vertical force vector. This arrangement also increases the length of the adductor musculature and thus the total muscle mass. We propose that the reduced pterygoid flange indicates a diminished role for the pterygoideus muscle, reflecting a shift of the majority of the bite force to the adductor mandibulae externus, pseudotemporalis, and adductor mandibulae posterior muscles. Reduction of the pterygoideus falsifies the dual adductor system hypothesis, in which kinetic inertia and static pressure coexist.
\end{abstract}

Ricardo Araújo. Huffington Department of Earth Sciences, Southern Methodist University, Dallas, Texas 75275, USA, rmaraujo@smu.edu and Museu da Lourinhã, Rua João Luís de Moura, 95, 2530-158 Lourinhã, Portugal Michael J. Polcyn. Department of Earth Sciences, Southern Methodist University, Dallas, Texas 75275, USA mpolcyn@smu.edu 
KEY WORDS: finite-element modeling; Plesiosauria; Libonectes morgani; feeding mechanics; muscular trade-off; adductor chamber

\section{INTRODUCTION}

We use 3D finite element analysis (FEA) to assess cranial performance and test feeding models in elasmosaurids by varying the morphology of specific anatomical structures of the skull of Libonectes. Elasmosaurids are derived plesiosaurs (Ketchum and Benson, 2010) and plesiosaurs themselves are among the most derived eosauropterygians (e.g., Liu et al., 2011). Eosauropterygia is the longest-ranging group of marine reptiles (Motani, 2009) and the largest group of Mesozoic marine reptiles (Rieppel, 2000), and eosauropterygians are unique in their inferred mode of locomotion (Robinson, 1975; Riess and Frey, 1991). However, fundamental aspects of their paleobiology remain poorly known (Rieppel, 2002). Plesiosaurs spanned from Early Jurassic to the latest Cretaceous and had a worldwide distribution (Ketchum and Benson, 2010; Benson et al., 2012). These marine creatures developed different bauplans (O'Keefe and Carrano, 2005), comprising various adaptations to a wide array of lifestyles and prey preference (e.g., Sato and Tanabe, 1998). Among plesiosaurs, elasmosaurids were longnecked, short-headed forms that were relatively common in the Late Cretaceous, along with the short-necked, longirostrine polycotylids. Elasmosaurids have been found in the Western Interior Seaway (Sato, 2003; Druckenmiller and Russell, 2008), Japan (Sato et al., 2006) and in several locations in the Southern Hemisphere (Wiffen and Moisley, 1986; Otero et al., 2012; Mateus et al. in press). One of the best-preserved specimens from the Western Interior Seaway is Libonectes morgani SMUSMP 69120 (Carpenter, 1997) from the Turonian of Texas, originally described by Shuler (1950) as Elasmosaurus morgani (Figure 1).

The feeding habits of elasmosaurid plesiosaurs are poorly known although there is some direct evidence of prey preference, namely teleost fishes (Cicimurri and Everhart, 2001). However, the biomechanics of the plesiosaur cranial features related to feeding remains unstudied. Plesiosaurs have large supratemporal fenestrae, reduced pterygoid flanges, and tall parietal crests. This unique cranial arrangement has been discussed briefly in the literature in the context of feeding mechanics (Taylor, 1992; Taylor and Cruickshank, 1993), and despite the lack of extant animals with equivalent feeding anatomy (McHenry et al., 2006), behavioral comparisons have been made between plesiosaurs and crocodilians (e.g. Taylor, 1992).

We know some skull structure reflects performance and function; however the presence of fasciae and aponeuroses make interpretation challenging in some cases (Curtis et al., 2011). Nonetheless, biomechanics informed by comparative anatomy allows at least large scale patterns to be discerned. Although skull structures may play other non-feeding roles in the evolution of biological forms (e.g., defense or sexual display); those reasons are not assessed here. Every mechanical engineering system must balance applied forces (i.e., direction and magnitude) with the material proprieties and dimensions (i.e., its morphology). In biological systems, this is a compromise between the forces imparted by muscles and the structural proprieties of bones. The biomechanical system is also influenced by the energetic cost of maintenance, growth, and repair of the musculoskeletal system (Alexander, 1968).

In order to understand the complex patterns of muscle action during jaw closure, Olson (1961) conceptualized two models of jaw adduction for a variety of vertebrates. The kinetic inertial model (Olson, 1961) involves rapid closure of the jaws, especially when the lower jaw is abducted by the adductor mandibulae muscles. In contrast, the static pressure model (Olson, 1961) consists of forceful closure of the jaws, primarily by the pterygoideus muscles. This model is exemplified by crocodilians, in which a larger area of muscle attachment produces greater force (e.g., enlarged pterygoid flanges for the pterygoideus attachment in crocodilians, see lordansky, 2000).

Taylor (1992) conducted the first mechanical analysis of feeding in the rhomaleosaurid Rhomaleosaurus, and Taylor and Cruickshank (1993) performed a similar analysis on Pliosaurus brachyspondylus. More recently, Rieppel (2002) performed a comprehensive study of feeding in basal sauropterygians. Taylor (1992) based muscular reconstruction on the gross anatomy of major muscles in lizards and crocodilians. Rieppel (2002) was exclusively concerned with ecomorphological implications in his adductor muscle reconstruction. The free-body analysis performed by Taylor (1992) provides a rough indication of the placement of 


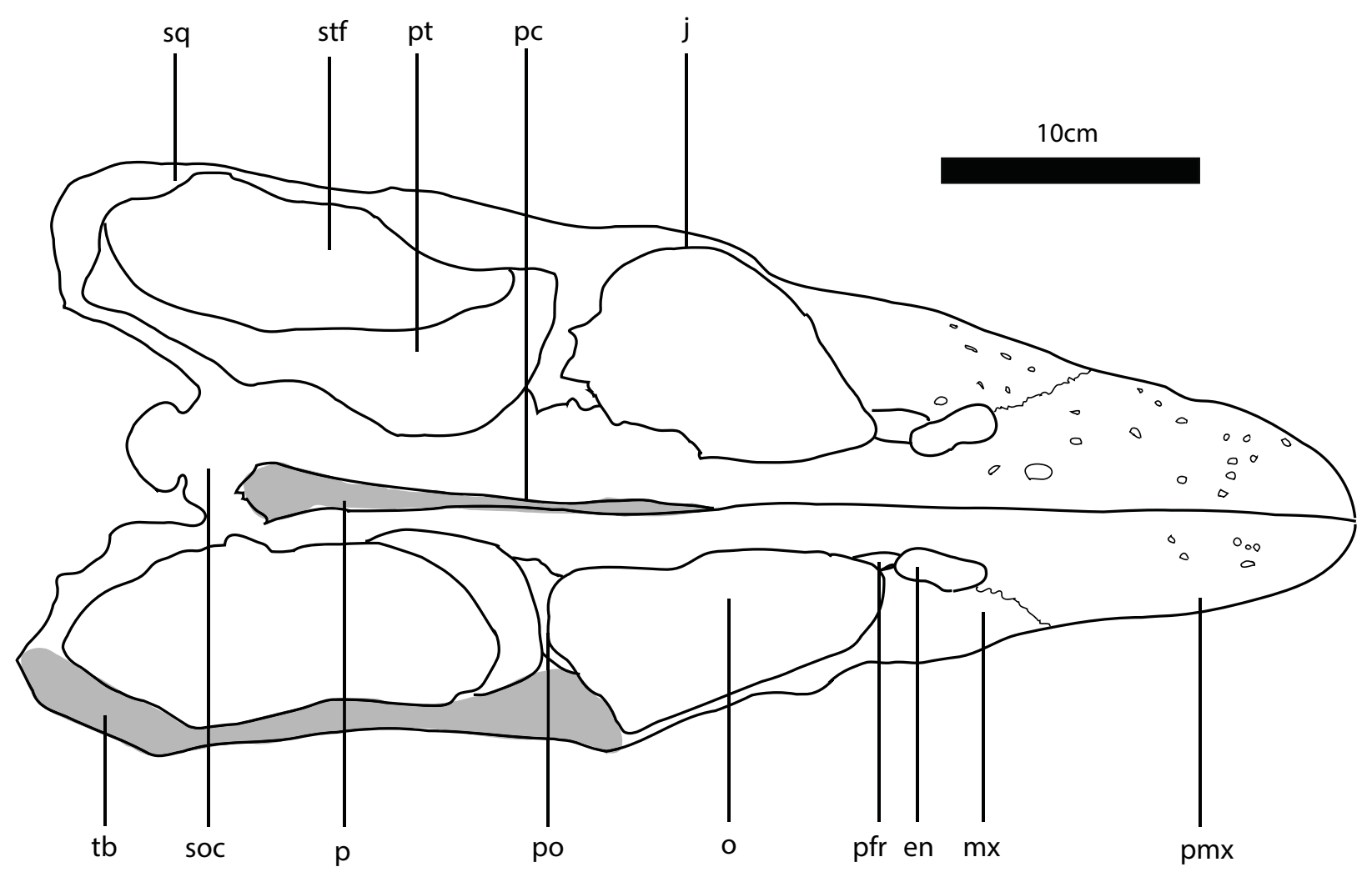

FIGURE 1. Libonectes morgani skull in dorsal view. Sq - squamosal; stf - supratemporal fenestra; pt - pterygoid; pc parietal crest; j - jugal; tb - temporal bar; soc - supraoccipital; p - parietal; po - postorbital; o - orbit; pfr - prefrontal; en - external nares; $\mathrm{mx}$ - maxilla; pmx - premaxilla.

stresses (Daegling and Hylander, 2000, pg. 542). However, neither Taylor (1992) nor Rieppel (2002) assessed the biomechanical effects of specific, functionally-relevant, features of the skull. The recent proliferation of cost-effective hardware and software has led to a spectacular increase in the use of finite element analysis for biomechanical studies (Rayfield, 2007), allowing quantitative appraisals that deal with highly complex geometries.

In extinct forms such as plesiosaurs, analyses such as those performed here should be done in the context of a reasonable phylogenetic hypothesis and a careful reconstruction of hard and soft anatomy. Plesiosauria is currently hypothesized to nest within Lepidosauromorpha (Rieppel, 1994; Rieppel and de Braga, 1996; Caldwell, 1996; de Braga and Rieppel, 1997; Motani et al., 1998). The broad consensus of their Lepidosauromorpha affinities allows extant Lepidosauria and Archosauria to be used as phylogenetic brackets (Bryant and Russell, 1992; Witmer 1995, 1997) for comparison and reconstruction of soft anatomy (e.g., Holliday and Witmer, 2007; Jones et al., 2009). Osteological correlates of the skull and comparison with extant taxa requires good preservation of the fossil under study. Muscle attachments in extinct taxa inferred from the musculature of extant animals can be ground-truthed using bone surface texture of fossils (Witmer, 1997; Hieronymus, 2006). Osteological correlates for muscle attachment are discernable by roughened, sculptured and striated surfaces, striated or punctate patterns (Taylor, 1992; Witmer, 1997) as well as ridges, crests, rims, fossae, and edges (e.g., Carrano and Hutchinson, 2002; Taylor, 1992; Witmer, 1997). lordansky (1964) gives an account of the osteological correlates existing on the ventral surface of the quadrate, which is dominated by crests of bone.

In this study, we present a quantitative comparative framework with which we evaluate feeding adaptations in elasmosaurid plesiosaurs, using Libonectes morgani SMUSMP 69120 as a model organism. We use computer modeling and finite element analysis to assess four hypotheses:

Hypothesis I. For jaw adduction function, we hypothesize that in Eosauropterygia the pterygoideus muscle was functionally replaced by the adductor mandibulae externus superficialis, medialis and profundus and pseudotemporalis, thus 
explaining the size difference among the areas of attachment of these muscle groups.

Hypothesis II. We hypothesize that enlarging the supratemporal fenestra decreases skull mechanical performance. According to beam theory, for the same diameters, peak stresses are correlated with longer beams.

Hypothesis III. We hypothesize that enlarging the height of the temporal bar increases skull mechanical performance. According to beam theory, when two rectangular beams of different height are bent along the axis parallel to the small edge of the rectangle, stresses will be higher in the beam with the smaller section area.

Hypothesis IV. We hypothesize that augmenting the height of the parietal crest increases skull mechanical performance and thus permits increased muscle force, which translates into increased bite force. According to beam theory, for two long cylinders subjected to the same bending moments, stresses are higher for the cylinder with the smaller diameter.

\section{ABBREVIATIONS}

mAMP, musculus adductor mandibulae posterior. mAME, musculus adductor mandibulae externus. mAMES, musculus adductor mandibulae externus superficialis. mAMEM, musculus adductor mandibulae externus medialis. mAMEP, musculus adductor mandibulae externus profundus. mPST, musculus pseudotemporalis. $\mathrm{mPT}$, musculus pterygoideus. FEA, Finite-element analysis. NURBS, Non-Uniform Rational Basis Spline. IGES, Initial Graphics Exchange Specification. CAD, Computeraided design. CT, Computed tomography. STB, shallow temporal bar variant model. LPC, low parietal crest variant model. SSF, small supratemporal fenestra variant model. LC1, Loading condition 1: finite-element simulation with no mAME action and scaled $\mathrm{mPT}$ forces. LC2, Loading condition 2: finite-element simulation with no $\mathrm{MPT}$ and normal (not scaled force) of mAME+mPST. SMUSMP, Southern Methodist University, Shuler Museum of Paleontology. EPB, Extant Phylogenetic Bracket. BM, Base model.

\section{METHODS}

\section{Muscle Reconstruction}

We use osteological correlates and the Extant Phylogentic Bracket methodology (EPB, Witmer, 1995) to identify muscle attachments in the elasmosaurid plesiosaur Libonectes morgani SMUSMP 69120. EPB allows determination of the levels of inference for soft tissue in extinct taxa based upon conservative patterns in extant taxa. A Level I inference implies that both extant taxa are anatomically congruent on the sites of attachment of a certain muscle. A Level II inference implies that reconstruction of some soft tissues differs between the two extant taxa, and a Level III inference of soft tissue for the extinct taxon that has no extant analog. We chose the rhyncocephalian Sphenodon punctatus and the crocodilian Alligator mississipiensis for our bracketing taxa. We employed other taxa such as turtles (Lutz et al., 1996; Werneburg, 2011) and lizards (Shinisaurus crocodilurus and Xenosaurus grandis, Haas, 1960, Varanus Lakjer, 1926; Frazzetta, 1962) to clarify muscle attachment sites. These taxa have been the subject of detailed myological studies (Lakjer, 1926; Haas, 1973; lordanski, 2000; Van Drongelen and Dullemeijer, 1982; Holliday and Witmer, 2007; Jones et al., 2009; Werneburg, 2011). Rieppel (2002) noted that the adductor muscles in reptiles are conservative in their loci of insertion and origin, thus variation in the shape of the skull affects muscle function and performance. It is important to note that in the case of adductor muscles, the area of attachment can be used as a proxy for muscle force because the attachments are mostly direct and not tendinous (Antón 1999, 2000; Hieronymus, 2006). This assumption is supported by the EPB and the presence of muscle scars on the expected areas of attachment.

For the assessment of osteological correlates, we examined the specimen (SMUSMP 69120) visually for areas of muscle attachment, but we could not identify extrinsic fibers density counts to infer muscle attachment areas (Hieronymus, 2006). Therefore, we used low-angle tungsten light and macrophotography to identify bone texture patterns and locate muscle attachment areas (Tumarkin-Deratzian et al., 2007) using an $18-55 \mathrm{~mm}$ focal distance lens with a working distance of $25 \mathrm{~cm}$ on a Canon ${ }^{\circ}$ EOS 1000D. The images were then postprocessed in Adobe Bridge ${ }^{\circledR}$ Camera RAW in order to enhance contrast and differentiate bone texture.

\section{Laser Scanning and 3D Model Building}

In this study, we employed laser scanning to capture a surface model of Libonectes morgani (SMUSMP 69120) using Scanstudio ${ }^{\circledR}$ and the NextEngine HD scanner. We used Rapidform $X O R \circledast$ to align the scan families and fused them to a final 3D model. We resurfaced the 3D scan data in Lightwave ${ }^{\circledR} 3 \mathrm{D}$ Modeler $v 9$ to create a simplified 

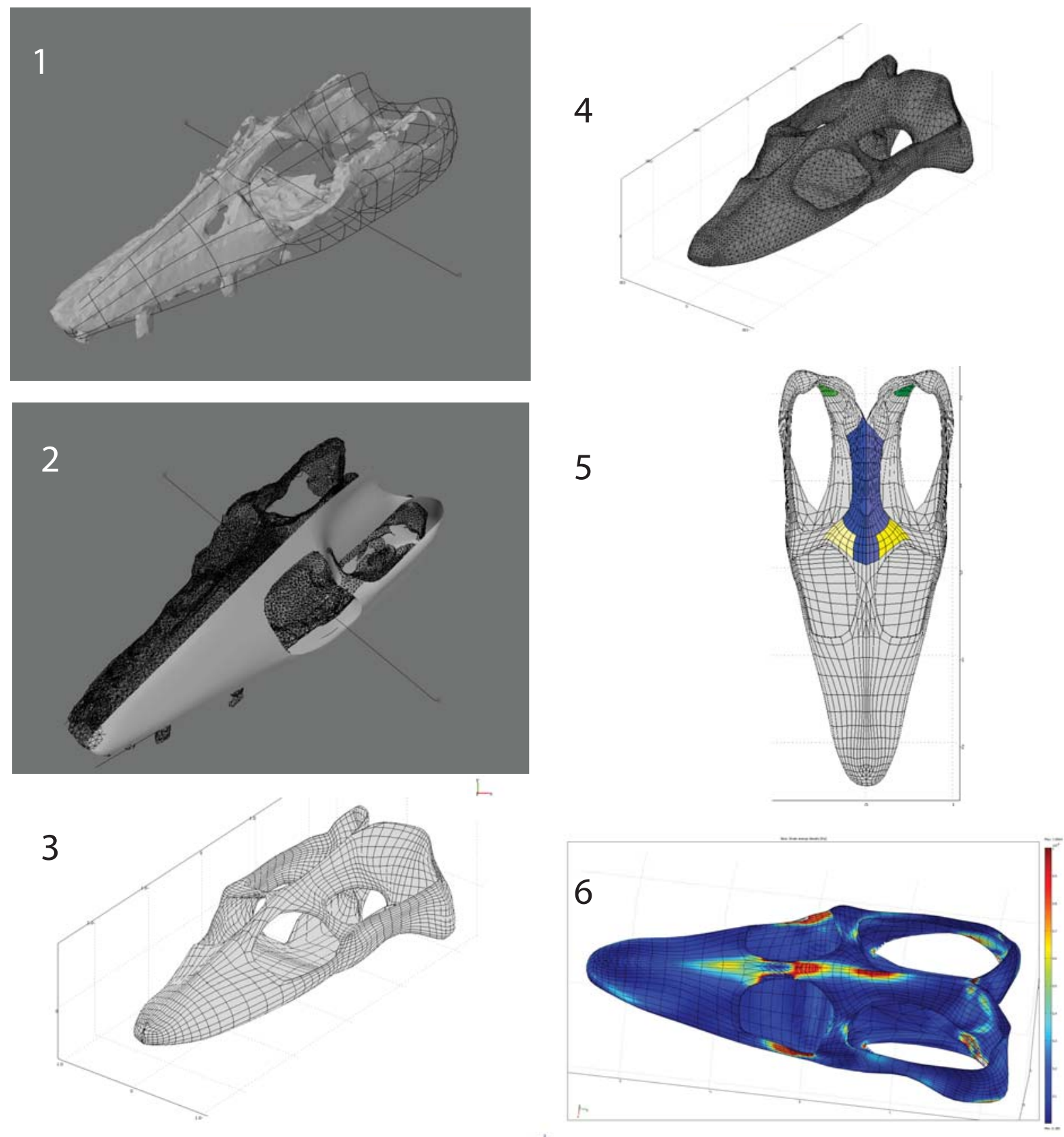

FIGURE 2. Workflow from laser scanning to finite-element analysis. 1 The base model was laser scanned using Scanstudio ${ }^{\circledR}$. 2 The 3-D modeling used NURBS spline surfaces to conform with the shape of the laser-scanned skull; this is done in Lightwave ${ }^{\circledR}$. 3 The NURBS surfaces facilitate remodeling according variants intended to be studied. 4 The models are meshed in the FEA software COMSOL Multiphysics ${ }^{\circledR} .5$ In COMSOL Multiphysics ${ }^{\circledR}$ the boundary conditions (loadings and constraints) are applied. 6 The results obtained are scaled to the same range in order to facilitate comparison.

spline NURBS (i.e., non uniform rational basis spline) model. See Figure 2 for the process flow employed here.

The surface model is essentially a thin-walled shell, composed of interconnected polygons that form the surface. We then "thickened" the walls, by creating an interior surface for the shell by mirroring the NURBS patches and displacing them a uniform distance along their normals, forming the watertight model. Thus, the modeled bone thickness is, approximately, the thickness of the actual specimen. 
Muscle attachment areas, model volume, and surface area were quantified using the 'Area Volume' tool, a downloadable Lightwave ${ }^{\circledR}$ plug-in. The Lightwave NURBS model was transferred to Rhino ${ }^{\circledR} 3 \mathrm{D}$, then exported as an IGES (Initial Graphics Exchange Specification) file, which is a tetrahedral 3D mesh. We then examined the resulting mesh under multiple loading conditions in Comsol® Multiphysics.

We imported the models as IGES files into Comsol ${ }^{\circledR}$ Multiphysics, in which the models were meshed using the free mesh tool and subjected to static analyses type with ideal constraint types and Lagrange-quadratic element type. For the initial model, the finite-element mesh had 76861 tetrahedral elements, with 34532 triangular boundary elements, minimum element quality 0.0354, and element/volume ratio $1.8 \times 10^{-5}$. The SSF (small supratemporal bar) model had 75622 elements, 409434 degrees of freedom, an element/volume ratio $1.46 \times 10^{-6}$, and minimum element quality 0.0502 . The STB (shallow temporal bar) model had 86543 elements, 4692390 degrees of freedom, an element/volume ratio $1.9 \times 10^{-5}$, and minimum element quality 0.0354 .

The advantage of this method is that NURBS models (or other polygon models for that matter) can be easily manipulated to create experimental variants. This method is practical for our purposes (i.e., testing the role of certain morphology predetermined conditions) and has been employed previously (e.g., Kupczik, 2008). NURBS models can be manipulated in a variety of CAD (computeraided design) modeling programs to create altered versions. Another advantage of using NURBS surfaces (and other parametric models) is that they employ a relative small number of vertices to define shapes compared to manipulating the large datasets employed when working directly with either CT scans or laser scans.

\section{Arthrology}

In building our models, we chose not to incorporate sutures because Sauropterygian skulls are effectively akinetic (Rieppel, 2002; Taylor, 1992; however, see also Bardet et al., 1999; Gasparini et al., 2002). Most of the sutures can only be seen on the bone surface, and details of interdigitations cannot be differentiated internally (Jones et al., 2011). Additionally, Herring and Tseng (2000) claim that even for vaulted sutures, the strains imparted on them may be significant, and sutures are less stiff than the centers of bones as demonstrated by in vivo studies (Rafferty and Herring, 1999). None- theless, we choose to treat the skull as a unit due to the presence of certain anatomical features indicative of an akinetic skull. These are: (1) a dorsoventrally wide upper temporal bar; (2) robust palatal and temporal articulations; (3) solid suturing of the paroccipital process; and (4) presence of structurally important bones (e.g., postorbital, ectopterygoid, and epipterygoid). We do, however, consider our treatment of the skull as a single unit a simplification appropriate to the hypotheses tested here.

\section{Mechanical Proprieties of Bone}

Gross mechanical properties of bone are known to be similar amongst amniotes (Erickson et al., 2002); however, little empirical data is available for reptiles. Additionally, variation in different types of bone tissue is not well-known, even for humans, although some data are available (Dechow et al., 1993; Rho et al., 1997; Bayraktar et al., 2004). For reptiles, published mechanical proprieties of bone are rare. American alligator (Alligator mississippiensis) femoral cortical bone has been reported as having a Young's modulus of 12.02GPa (Currey, 1988), and the value for Crocodylus sp. femoral cortical bone is 5.63GPa (Erickson et al., 2002). The most complete dataset for Alligator mississippiensis is given by Daniel and McHenry (2001), providing a Young's modulus of 10GPa, Poisson's ratio 0.4 , and a density $2.3 \mathrm{~kg} / \mathrm{m}^{3}$. Although we employ the parameters given by Daniel and McHenry (2001), we accept that bone is an anisotropic material (e.g., Tzukrov et al., 2009), and acknowledge the simplifications required by our modeling technique and selection of bone properties.

\section{Model Variants and Boundary Conditions}

We employed variants of the base model (BM) with a 'small supratemporal fenestra' (SSF), 'shallow temporal bar' (STB), and 'low parietal crest' (LPC) to assess the effects of varying morphologies. These variant models exemplify the plesiomorphic condition seen in basal sauropterygians (sensu Rieppel, 2000) and allow the functionally-relevant variables to be studied independently (Table 1). Given the aims of our experiments, we maintained the same fixed constraints for all models, simulating a symmetric bite in the anteriormost tip of the skull (Figure 3). We constrained the area corresponding to the first premaxillary teeth and a small area on the ventral part of the two quadrates. The myological reconstruction of the adductor muscles allowed measurement of the angles of the muscles between the areas of 
TABLE 1. Areas for the muscles origins in the different variant models.

\begin{tabular}{ccccccc} 
& \multicolumn{7}{c}{ Area $\left(\mathbf{c m}^{\wedge} \mathbf{2}\right)$} \\
\cline { 2 - 7 } & mPST & mAME & mAMP & mAMES & mDM & mPT \\
Initial model & 11.3213 & 58.3881 & 29.4737 & 43.5531 & 13.1584 & 24.3531 \\
Low parietal & 9.09129 & 34.8869 & 37.6998 & 45.681 & 13.1584 & 21.0722 \\
Thin temporal & 9.87854 & 52.74 & 37.2582 & 28.9364 & 18.912 & 22.0872 \\
Small supratemporal & 11.2411 & 31.9708 & 36.9917 & 27.8797 & 23.2992 & 13.3696
\end{tabular}

origin and attachment (Table 1 ) in order to determine the force vector orientation (Table 2). We used a protractor for these measurements. We calculated two components for each vector with the following exceptions in which a single component was calculated: $\mathrm{mPT}$, due to the complexity of the muscle; mAMES, in which only the dorsoventral component was calculated due to the nearly vertical orientation of the muscle. We calculated only the dorsoventral component of the mDM because the retroarticular process is not entirely preserved in Libonectes. We also excluded the pseudotemporalis profundus from our model due to its minimal influence on the total budget of muscle action during adduction (see Moreno et al., 2008; Curtis et al., 2010). We applied the loading to homologous areas of the mesh, although their exact position from model to model can vary to some degree, reflecting the model variants geometry. As the area of attachment varies, so does the total force exerted on the skull. These differences in area are presented in the Table 1.

\section{FEA Experiments}

In order to assess the hypothesis of the muscular trade-off $(\mathrm{H} 1)$ between the pterygoideus and adductor mandibulae externus, we ran two different loading conditions. For the first loading condition (LC1) we linearly scaled the force of the $\mathrm{mPT}$ as if it had the same area as adductor mandibulae externus plus the pseudotemporalis (mAME+ mPST) but removed completely the latter muscle forces. In the second loading condition (LC2) we removed the $\mathrm{MPT}$ force completely and maintained the forces for the rest of the muscles. Within amniotes, forces produced by muscles of the same size
1

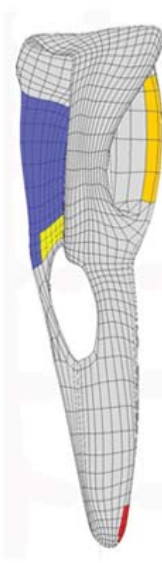

2

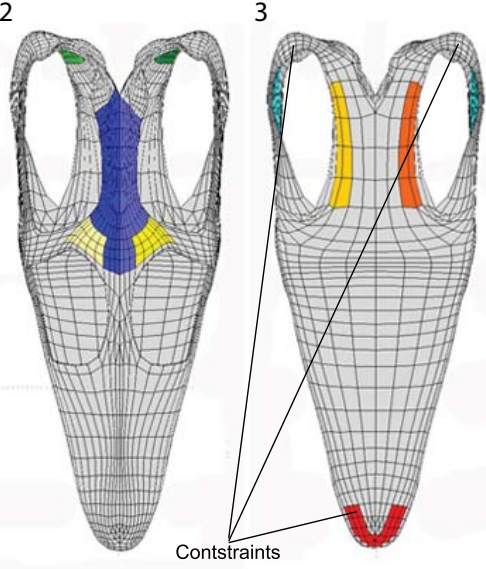

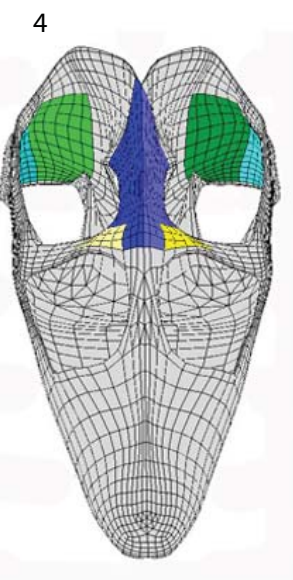

5

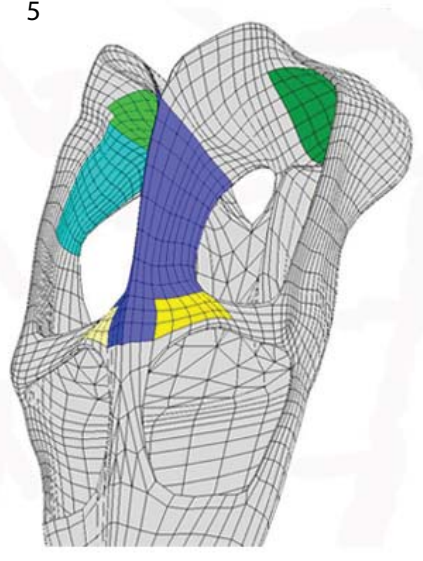

FIGURE 3. Base skull model in various views with the boundary conditions. 1 Lateral view. 2 Dorsal view. 3 Ventral view. 4 Anterodorsal view. 5 Laterodorsal view. Boundary conditions: light blue - area for origin of left MAMES origin, dark blue - area for origin of right MAMES origin; light yellow - area for origin of right MPst origin; dark yellow - area for origin of right MPst origin; light green - area for origin of right MAMP origin; dark green - area for origin of right MAMP origin; light orange - area for origin of left MPt origin; dark orange - area for origin of right MPt origin. 
TABLE 2. Angles for the orientation of the different forces produced by the muscles in all models.

\begin{tabular}{lcccccc} 
& \multicolumn{6}{c}{ Angles between forces components $\left(^{\circ}\right)$} \\
\cline { 2 - 7 } Dorsoventral and mediolateral axis & 25 & 23 & 0 & 0 & 0 & 35 \\
Anteroposterior and mediolateral axis & 0 & 0 & 0 & 0 & 0 & 70 \\
Dorsoventral and anteroposterior axis & 0 & 0 & 31 & 0 & 0 & 36
\end{tabular}

are sub-equal (Carlson and Wilkie, 1974; Weijs and Hillen, 1985; Thomason, 1990). However, the same muscle stress was used for all models, thereby allowing comparable results. The forces used for each muscle can be calculated by multiplying the area by stress value used $392000 \mathrm{~N} / \mathrm{m}^{2}$, the maximum recorded for amniotes.

The BM was subjected to the abovementioned boundary conditions (Figure 3). The variants of the base model SSF, STB, LPC were subjected to the same loading conditions and constraints as the BM.

\section{RESULTS}

\section{General Description of the Skull of Libonectes}

Here we present a brief description of the skull of Libonectes, for a detailed description see Carpenter (1997). The premaxillae form the majority of the rostrum and bear five teeth. The premaxillae contact the maxillae posteriorly and medially form the medial rim of the posteriorly-retracted external nares. On the median portion of the skull, the external nares contact the thin frontal. The posterior extent of the frontal contacts the large parietal, which forms the posterior portion of the orbit and the medial walls of the supratemporal fenestrae. The parietal also contacts the thin postorbital, whose lateral articulation with the jugal forms the lateral border of the orbit. The temporal bar is thus formed by both the jugal (anteriorly) and by the squamosal (posteriorly). The squamosal meets posteriorly with the quadratojugal, which is tightly articulated with the quadrate. In palatal view, the premaxilla contacts the vomers medially. The vomers also contact the maxillae, forming the medial border of the internal nares and posteriorly contact the anterior tips of both the palatines and pterygoids. The medially-located pterygoids form most of the ventral exposure of the palate and bear a small posteriorly-located inflated linear protuberance that forms the medial wall of the supratemporal fenestra. This structure is interpreted as the pterygoid flange. The palatines are bordered by the pterygoids medially, by the maxilla laterally and contact the ectopterygoid posteriorly. From the median section of the posterior interpterygoid vacuity arises the crested parasphenoid, which contacts the basioccipital posteriorly.

\section{Arthrology}

The premaxilla-maxilla joint is a well-defined, immobile, deeply interdigitating suture (sutura serrata). The joint rises obliquely from the fourth premaxillary tooth and terminates at the external naris. The maxilla-jugal joint, visible medially, is also sutura serrata. The lateral wall does not preserve the characteristic interdigitating pattern. The maxilla extends posteriorly to the level of the first third of the supratemporal fenestra, with a dorsoventrally high contact with the jugal. The jugal-squamosal joint forms a conspicuous, posteriorlydipping, linear sutura serrata. The length of the serratae are longer $(7,70-11,53 \mathrm{~mm})$ than in the premaxilla-maxilla joint (4,78-1,43 $\mathrm{mm})$. The frontoparietal, premaxillary-prefrontal, postorbitaljugal, and postorbital-parietal joints are also linked by sutura serrata; however, the prefrontal is overlaped laterally by a simple scarf joint (sutura plana) with the maxilla. The pterygoid-squamosal joint and the vomers, palatines, pterygoids and parasphenoid are joined by sutura serrata. The dorsal expansion of the ectopterygoid meets the jugal medially and interdigitates with the surface of the jugal. Together with the basisphenoid, the ectopterygoid forms an important link between the palate and the skull roof. The quadratosquamosal joint forms a dorsoventrally-oriented suture. The two bones seem to be fused anteriorly, but the two bones are juxtaposed posteriorly. The skull elements of Libonectes are mostly united by compressionally-resistant sutura serrata, suggesting little sutural mobility. Flexure would be a function of the elasticity and microanatomical aspects of the bone. It is reasonable to consider sutural areas as less elastic than more central portions of the bones, but we have made no attempt to model this.

\section{Osteological Correlates of Muscle Attachement in Libonectes}

In Libonectes, the surface of the parietal is highly sculptured (origin of the mAMEM and 


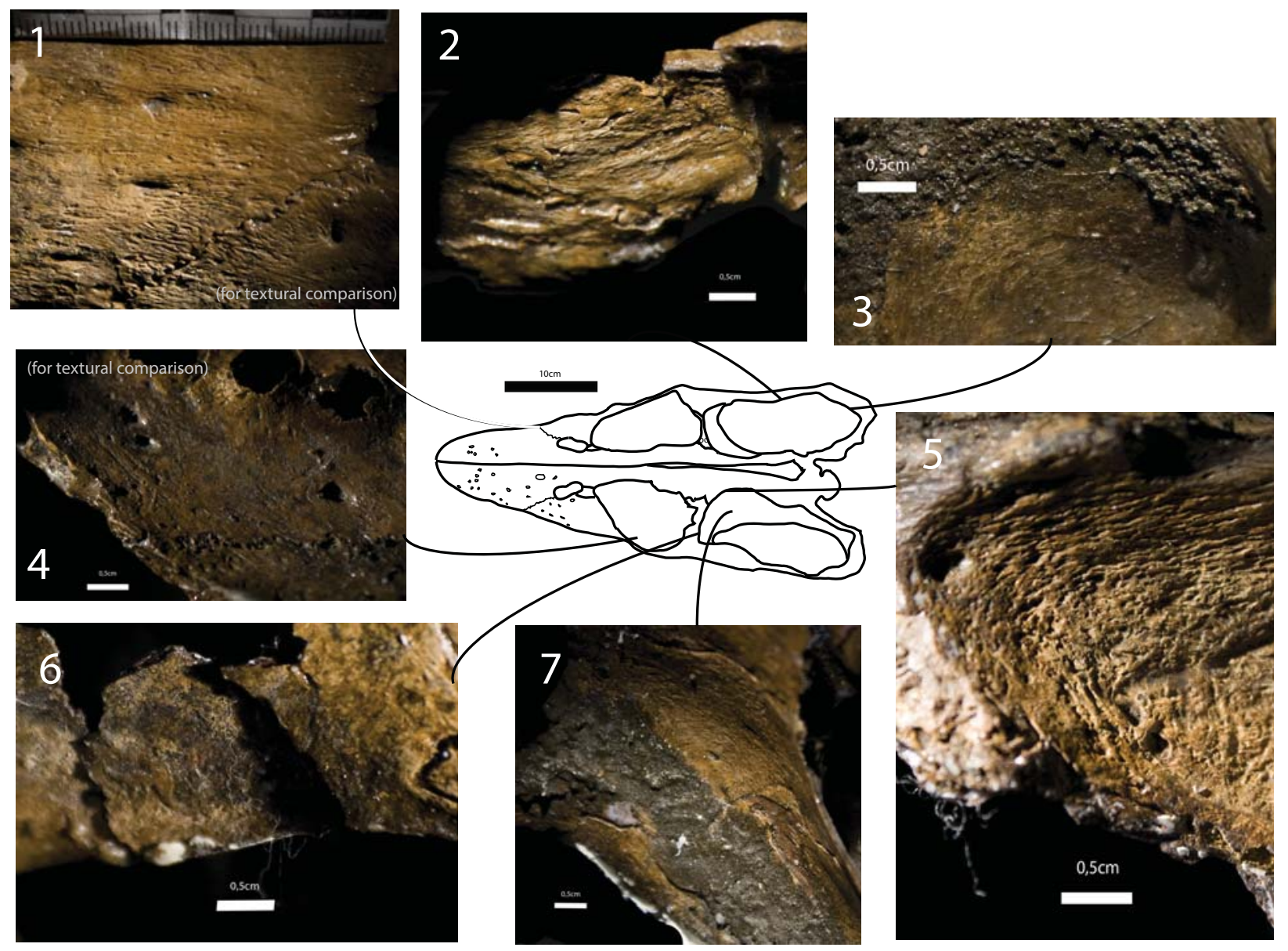

FIGURE 4. Osteological correlates in the cranium of Libonectes morgani. 1 Periosteum texture on the premaxillamaxilla for textural comparison with other regions of the skull, note the ornamented surface of the bone and the presence of several elongated foramina. 2 Medial view of the temporal bar at the level of the squamosal jugal suture; note the deeply striated and rugose texture of the bone where the mAMES most likely inserted. 3 In anterodorsal view, the posteriormost portion of the temporal fenestra; note excavated form of this section of the skull where the mAMP most likely inserted. 4. Dorsal view of the palate in the orbital region for textural comparison of the periosteum; note the smooth surface of the bone. 5 The highly pitted and rugose texture of the parietal crest is suggestive of the origination of the mAMEM and mAMEP. 6 Finely pitted surface of the posterior surface of the postorbital where the mPST most likely inserted. 7 Finely pitted lateral walls of the pterygoid where most likely the mPT inserted. Scale bar equals 0.5 $\mathrm{cm}$.

mAMEP). The parietal surface has randomly-oriented striations within the pitted surface of the periosteal bone (Figure 4). The anterior surface of the quadrate and squamosal has an concavity; however, the surface is smooth (origin of the mAMP). The medial wall of the right jugal has an anteroposteriorly striated area (origin of the mAMES), although the periosteum pattern is difficult to discern. The lateral wall of the pterygoid is smooth but medially depressed, and the ventral boss is rugose (origin of the $\mathrm{mPT}$ ). The posterior wall of the postorbital is smooth and has a deep concavity (origin of the mPSTS).
The adductor fossa of the mandible is heavily sculptured by small pits and anastomosing striations (Figure 5). The coronoid bone is largely smooth, but increasingly pitted dorsally (insertion of mAMP). The apex of the coronoid eminence is eroded. On the lateral wall of the mandible, the angular is deeply striated (insertion of $\mathrm{mPt}$ ). Most of the surangular surface is smooth except dorsally, where the edge that runs from the glenoid to the coronoid eminence is dominated by striae near the glenoid (insertion of $\mathrm{mPt}$ ). The surangular is pitted dorsally. On the medial surface of the mandible there are two rugosities ventral to the glenoid cavity (insertion of mPST). These may be pathological, 


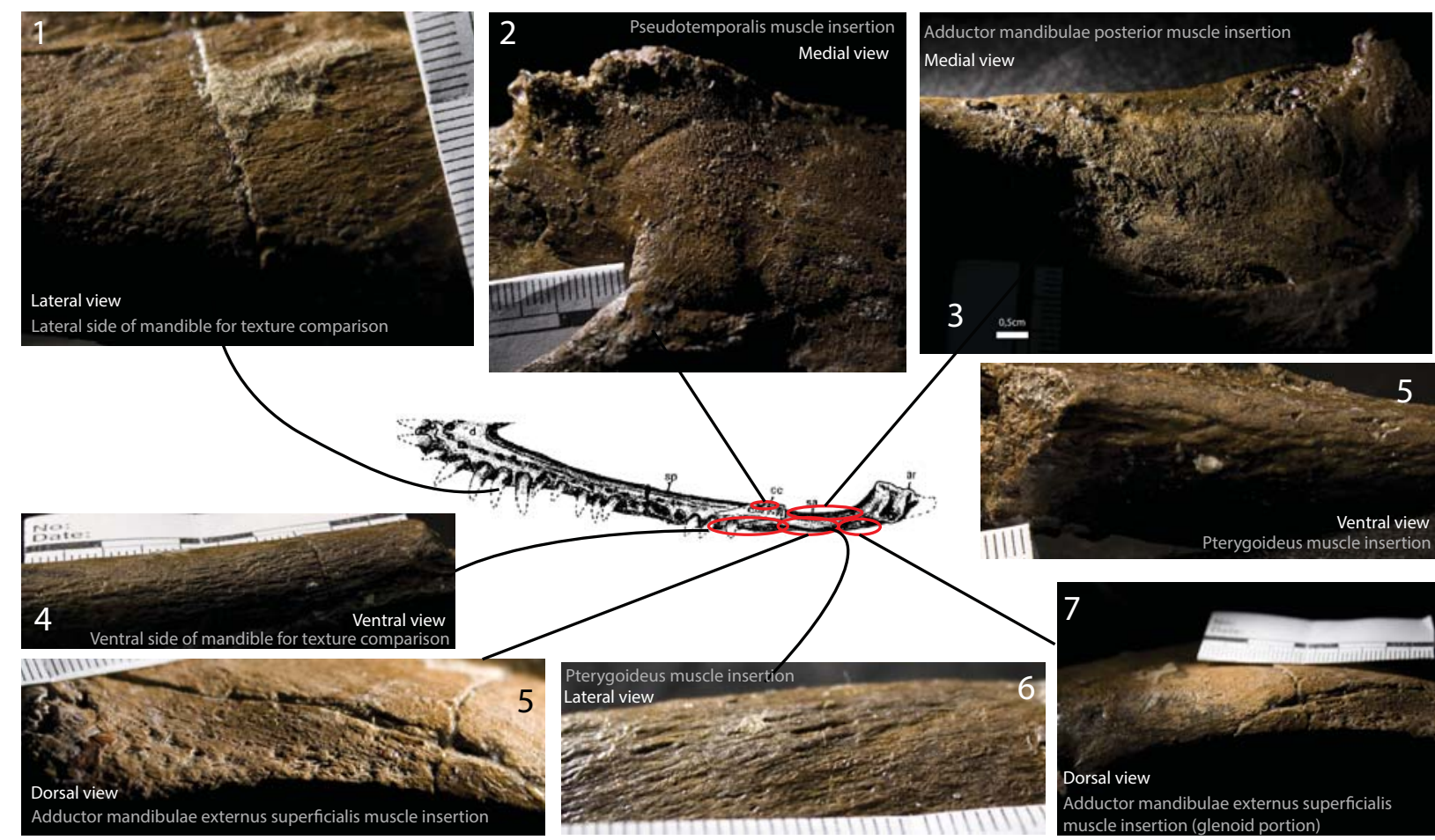

FIGURE 5. Osteological correlates in the mandible of Libonectes morgani. 1 Lateral view of the anterior portion of the mandible; the smooth but slightly ornamented texture of this section of the bone contrasts with the areas where muscles insert. 2 In medial view near the coronoid the bone texture is highly but smoothly pitted suggestion the area of insertion of the MPST. 3 Medial view of the mandible posterior to the coronoid; note the finely pitted area, tentatively the insertion of the mAMP. 4 Ventral view of the mandible with fine ornamental striations (contrast with the striations of the $\mathrm{mPT}$ insertion). 5 Strongly remodeled bone periosteum presenting a wavy pattern where a portion of the $\mathrm{mPT}$ inserted. 6 Dorsolateral view of the mandible near the coronoid; presumable mAMES insertion demonstrating deeply pitted bone texture. 7 Lateral view of the mandible demonstrating deep striations for presumable insertion of the mPT. 8 Dorsal view of the glenoid region with deeply pitted surface possibly for the insertion of the mAME.

but the possibility muscle attachments in these areas cannot be rejected. There is a slight rim on the surangular, extending posteriorly along the line of the glenoid (insertion of mAMEM).

\section{Muscle Reconstructions}

In addition to the interpretations above, we use the EPB to assess the cranial and mandibular muscle attachments.

Musculus adductor mandibulae externus superficialis (mAMES): Origin - In Alligator, it originated from the ventrolateral surface of the quadrate and quadratojugal (Holliday and Witmer, 2007), see Figure 6. In Sphenodon, it originates on the medial wall of the upper temporal bar, extending ventrally along the fascia that connects to the lower temporal bar (Jones et al., 2009). The anteroposterior extension of the jugal and the anterior portion of the squamosal form part of the origin of the levator anguli oris (a subdivision of mAMES ) in Sphenodon (Haas, 1973). In this case, none of these taxa seem to be the right homologues. Neither Libonectes had two temporal bars interconnected by a fascia, nor the quadrate and quadratojugal are horizontally oriented. It is reasonable to assume, though, that the medial wall of the squamosal and anteromedial parts of the quadrate served for insertion of the mAMES. In turtles, the origins of the adductor mandibular externus originates in part on the medial wall of the opistotic bone (Lutz et al., 1996; Werneburg, 2011), and in Shinisaurus the fronto-postorbital forms the temporal bar (Haas 1960, p. 35). In Calotes emma, which has a remarkably well-developed mAMES, the mAMES originates on the postfrontal, squamosal, jugal, and quadrate (Lakjer, 1926, Haas, 1973). Thus, we infer that the mAMES originated on similar areas in Libonectes. Rieppel (2002, p. 294, figure 4) only considers mAMES1-b; however, this shows only part of the area of attachment of the mAMES, and more anterior fibers are thus disregarded. In Libonectes, as in the extant taxa stud- 

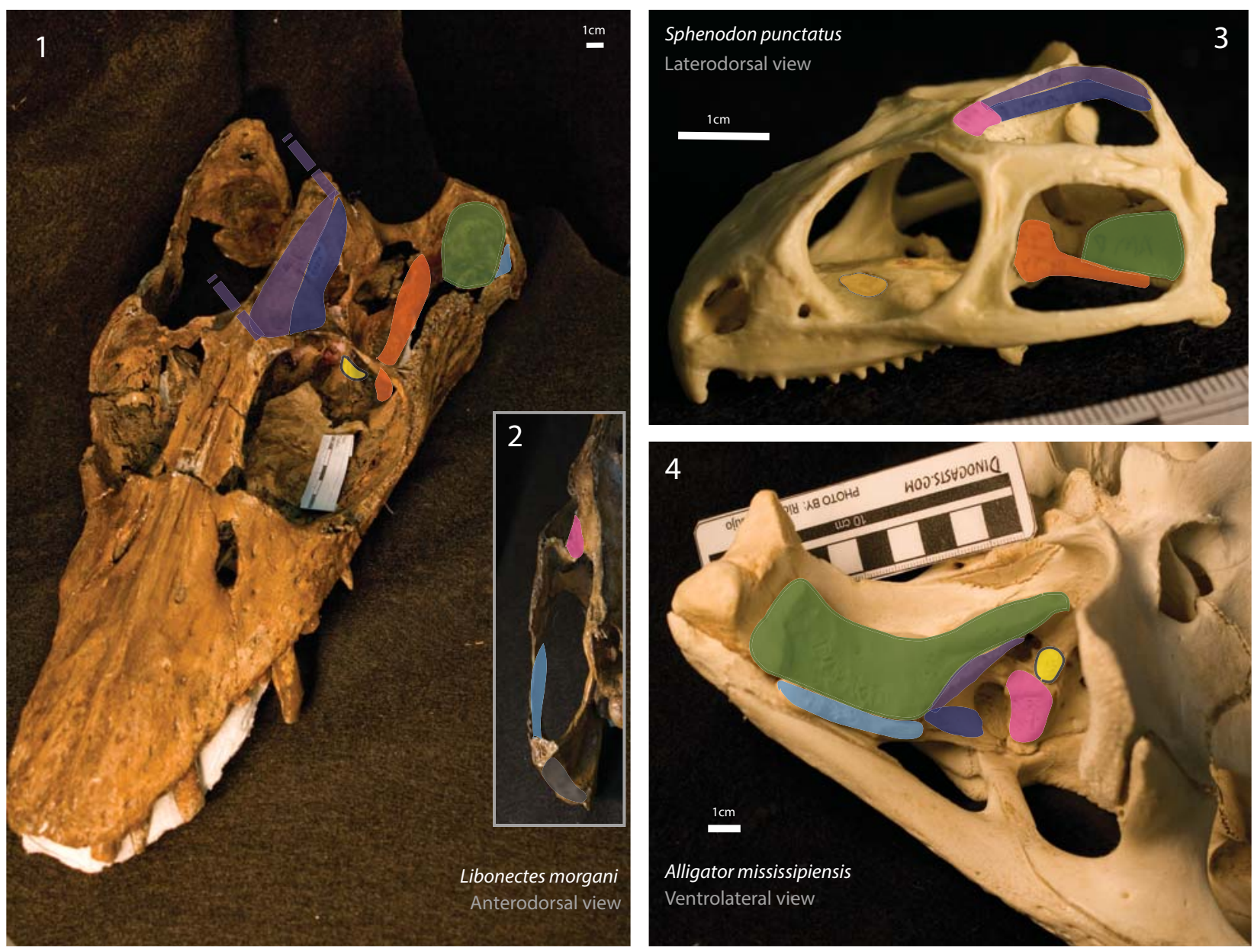

FIGURE 6. Muscle attachments in Libonectes morgani, Sphenodon puncatus and Alligator mississipiensis. 1 Libonectes morgani skull in laterodosal view and its adductor chamber musculature origins. 2 Inset of the Libonectes morgani skull in posterodorsal view depicting the supratemporal fenestra and adductor chamber musculature origins. 3 Sphenodon punctatus skull in laterodorsal view and its adductor chamber musculature origins based on Jones et al. (2009). 4 Alligator mississipiensis skull in ventrolateral view depicting the adductor chamber region and its musculature origins. Grayish dark blue: mAMEM; Dark blue: mAMEP; Light blue: mAMES; Light green: mAMP; Gray: mDM - musculus depressor mandibulae; Orange: mPt; Yellow: mPstP; Pink: mPstS.

ied, the medial wall of the temporal bar (squamosal and jugal) forms the origin for mAMES, which is consistent with the osteological correlates that have on the medial wall of the right jugal. Level II inference (according to Witmer 1995, levels of inference cited hereinafter are based upon this reference).

Insertion - In Sphenodon, the adductor mandibulae externus superficialis inserts on the lateral part of the coronoid and surangular, as well as on the posterior part of the dentary (Jones et al., 2009), (see Figure 7). The ventral border of the insertion is limited by a ridge extending anteroposterioly, as in basal eosauropterygians (Rieppel, 2002). In Alligator and Caiman, it attaches on the dorsal surface of the surangular, lateral to the insertion of adductor mandibulae externus medialis (mAMEM) (Van Drongelen and Dullemeijer, 1982; Holliday and Witmer, 2007). In the extant taxa analyzed, the insertions are posterior to apex of the coronoid eminence, abutting the lateral margin of the articular surface. In Libonectes, there is a gentle shelf extending anteroventrally, posterior to the coronoid eminence also and parallel to the articular surface where the majority of the mAMES would presumably inserted. There is a deep pit lateral to the articular surface that probably serving as a point for tendinous attachment. Rieppel (2002) suggests that this insertion was located more ventrally in other non-plesiosaur sauropterygians. Level I inference. 

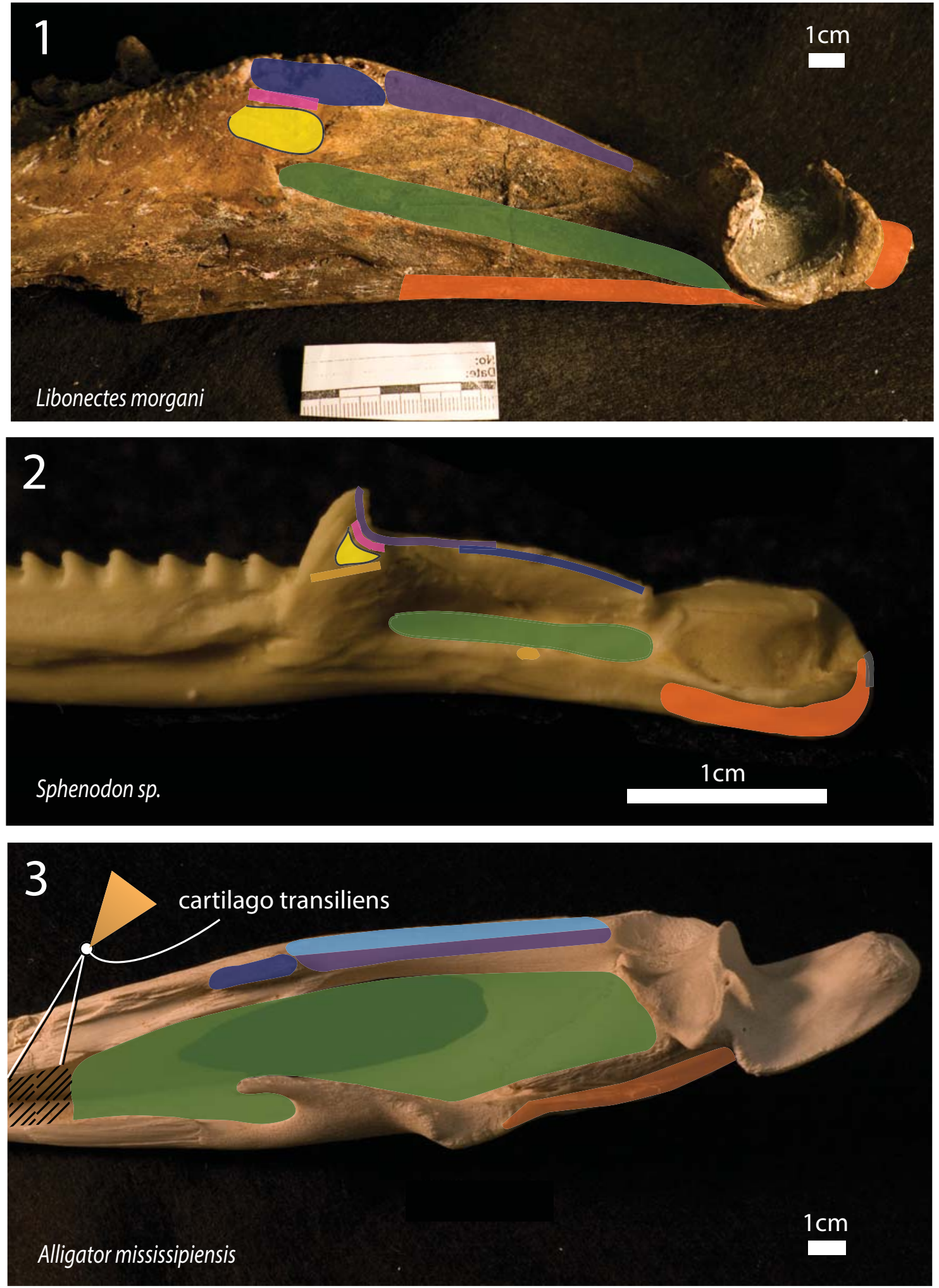

FIGURE 7. Mandible insertions in Libonectes morgani Sphenodon puncatus and Alligator mississipiensis. 1 Libonectes morgani medial view of the posterior portion of the mandible. 2 Sphenodon punctatus medial view of the posterior portion of the mandible. 3 A. mississipiensis medial view of the posterior portion of the mandible. Purple: mAMEM; Dark blue: mAMEP; Light blue: mAMES; Light green: mAMP; Gray: mDM - musculus depressor mandibulae; Orange: $\mathrm{mPt}$; Yellow: mPstP; Pink: mPstS. 
Musculus adductor mandibulae externus medialis (mAMEM): Origin - In Sphenodon, the adductor mandibulae externus medialis originates on the dorsal surface of the parietal crest, dorsal to the adductor mandibulae externus profundus (mAMEP), and extends posteriorly to the anterior wall of the squamosal (Jones et al., 2009). In Alligator, it is oriented mediolaterally, along the anteroventral part of the quadrate (Holliday and Witmer, 2007, p. 463-464). In Libonectes, it originated on the dorsal surface of the parietal crest, extending from the posterior end of the nasal to the posterior end of the parietal (Figure 6). The parietal surface in Libonectes is highly sculptured (Figure 4). In Alligator the mAMEM has its origin on the medial part of the skull, directly dorsal to the mAMEP. The temporal opening is occupied by the MAMEP in some turtles (Lutz et al., 1996, Werneburg, 2011), and the supratemporal fenestra in snakes, which have a remarkably high sagittal crest, is associated with the origin of both the MAMEM and mAMEP. Level I inference.

Insertion - In Sphenodon, the MAMEM insertion occupies a small area from the apex of the coronoid eminence to a point halfway to the glenoid (Jones et al., 2009, figure 25). In Caiman and Alligator, there is an anterior tuberosity on the coronoid eminence for tendon attachment, (Iordansky, 1964, Van Drongelen and Dullemeijer, 1982, Holliday and Witmer, 2007). The apex of the coronoid eminence is roughened in Libonectes, as in crocodilians. Contrarily to what is seen in crocodilians, there is no shelf on the dorsal surface of the surangular in Libonectes; it forms a sharp edge. This indicates that the area for attachment of the mAMEM is relatively small and possibly restricted to the coronoid eminence, because the dorsal surface of this edge still must bear the mAMEP (Figure 7). In Sphenodon and turtles (Jones et al., 2009, Werneburg, 2011), there is an aponeurosis extending from the coronoid for insertion of these muscles, and this complex structure could presumably be present in Libonectes as well. Level I inference.

Musculus adductor mandibulae externus profundus (mAMEP): Origin - In Sphenodon, the mAMEP originates either on the lateral crest of the parietal and on the anterior wall of the squamosal (Jones et al., 2009). In Alligator, it originates on the ventrolateral surface of the parietal. Although it is not preserved in Libonectes, the anterior wall of the squamosal is not a probable point of origin because in other elasmosaurids (e.g., Callawayasaurus) the parietal and squamosal are separated by a high parietal crest (Welles, 1962) that most likely served for insertion of the mAMEM. Thus, the origin in Libonectes is the parietal as well and the probable point of the insertion is the posteroventral portion of the parietal (Figure 6). Level I of inference.

Insertion - In Sphenodon, the insertion overlaps medially the anterior extension of the mAMEM, then, continues posteriorly to the glenoid border (Jones et al., 2009; figure 251 and 2). In Alligator, insertion is on the dorsomedial surface of the coronoid eminence of the surangular (Holliday and Witmer, 2007, table 4). The attachment area is therefore similar to the mAMEM in Libonectes, only more medially and posteriorly located along the sharp surangular edge that reaches the glenoid (Figure 7). Level II inference.

Musculus adductor mandibulae posterior (mAMP): Origin - In Sphenodon, this muscle originates from the anterior wall of the quadrate (Jones et al., 2009). In Alligator, it inserts primarily on the ventral part of the quadrate, with part extending to the vertically oriented wall of the pterygoid (Holliday and Witmer, 2007). Crocodiles bear a horizontal quadrate, homologous to the anterior face of the quadrate in most diapsids. In Libonectes, the smooth anterior surface of the quadrate and squamosal are concave. In this taxon, the muscle inserted either on the anterior wall of the quadrate and squamosal, both of which form the posteriormost part of the adductor chamber (Figure 6). In Callawayasaurus, the dorsal region of the squamosal is greatly expanded, possibly reflecting the origin of a large adductor mandibulae posterior (O'Keefe, 2001, figure 14). Level I inference.

Insertion - The insertion of the mAMP is conservative in many taxa (Sphenodon, Alligator, Testudinata, Shinisaurus and Xenosaurus), occupying the adductor fossa and partially filling the Meckel's groove (Haas, 1960; Holliday and Witmer, 2007, Iordansky, 1964; Van Drongelen and Dullemeijer, 1982; Jones et al., 2009). In Alligator and turtles, the anterior portion of the adductor fossa still serves for insertion of the pseudotemporalis superficialis muscle, by means of the intramandibularis muscle forming the cartilago transiliens (Holliday and Witmer, 2007). The cartilago transiliens is connective tissue that joins the intramandibularis muscle and the pseudotemporalis superficialis. In Libonectes, on the dorsal region of the adductor fossa, muscle scars are visible in the form of anastomosing rugosities (Figure 7). The ventral border of the adductor fossa is limited by a shelf that extends posteriorly for two-thirds of the 
distance between the apex of the coronoid and the articular surface. Level I inference.

\section{Musculus pseudotemporalis superficialis} (mPSTS): Origin - In Sphenodon, the mPSTS originates on the medial half of the anterior part of the supratemporal fenestra, the parietal and the postfrontal (Jones et al., 2009). In Alligator, it originates on the posterior wall of the laterosphenoid (Holliday and Witmer, 2007, p. 463-464). Although there is some variation of origin, the pseudotemporalis superficialis originates on the posterodorsal wall of the postorbital in Shinisaurus, Xenosaurus (Haas, 1960), Ctenosaura and Calotes (Haas, 1973). In Libonectes, part of the postorbital is not preserved, and only a thin plate of bone remains ventrally. The posterior wall of the postorbital is smooth, but has a deep concavity. The posterodorsal wall of the postorbital is the most likely region for origin of the pseudotemporalis (Figure 6). Level II inference.

Insertion - In Sphenodon, the insertion of the MPSTS is on the medial surface of the coronoid, posterior to the apex of the coronoid eminence, and immediately ventral to the mAMEM insertion (Jones et al., 2009, figure 25-1). A similar insertion is seen in Shinisaurus (Haas, 1960, p. 28). In Alligator, the insertion is more complex since it inserts on the cartilago transiliens (Holliday and Witmer, 2007, figure 10B). The intramandibularis muscle inserts on the anterior portion of the adductor fossa (Holliday and Witmer, 2007, figure 10B). Similarly, in turtles, the pseudotemporalis muscle inserts on the "medial internal tendon to [the] lower jaw" (Lutz et al., 1996, table 2.1, p. 63 see also Werneburg, 2011). The reconstruction of this muscle is thus equivocal in Libonectes. There are two possibilities; (1) insertion takes place on the coronoid bone, medial to the apex of the coronoid eminence, or (2) insertion takes place more ventrally on the anteroventral surface of the adductor fossa. Due to the lepidosauromorph affinities of plesiosaurs (e.g., Motani et al., 1998), it seems more likely that insertion was on the coronoid bone (see Figure 7). Level II inference.

Musculus pseudotemporalis profundus (mPSTP): Origin - In Sphenodon, it mainly inserts on the lateral edge of the parietal and epipterygoid (Jones et al., 2009, figure 15B and figure 27). In Alligator, this muscle originates in the ventrolateral surface of the laterosphenoid (Holliday and Witmer, 2007, figure 5A). According to Lakjer (1926) and Haas (1973), in Varanus this muscle originates roughly on the area of the ventral surface of the parietal and possibly the anterolateral part of the postorbital, possibly similar origins as in Libonectes. This region is highly sculptured as is the rest of the parietal (Figure 4). The epipterygoid in Libonectes is only composed by a small and thin flange of bone arising from the pterygoid. Furthermore, it does not have connection with the dorsal roof of the skull. Thus, the ventral surface of the parietal and the anterolateral part of the postorbital, forming the anterior wall of the supratemporal fenestra, are the best candidates for the origin of pseudotemporalis profundus muscle (Figure 6). Level II inference.

Insertion - The pseudotemporalis profundus inserts on the coronoid, contiguous ventrally with the insertion of the pseudotemporalis superficialis muscle (Jones et al., 2009, figure 25-2). In Alligator the mPSTP inserts on the posterodorsal edge of the angular (Holliday and Witmer, 2007, table 4). Similar to the pseudotemporalis superficialis muscle, it is difficult to assess the condition for the pseudotemporalis profundus muscle in Libonectes. Due to the lepidosauromorph affinities of Sauropterygia, we opt for an insertion ventral to the MPSTS and dorsal to the opening for the adductor fossa (Figure 7). Level I inference.

Musculus pterygoideus (mPT): Origin - In Sphenodon, the pterygoideus muscles are subdivided into the pterygoideus typicus and the pterygoideus atypicus. The pterygoideus typicus originates on the ventrally projecting pterygoideus process, and also on the laterally-exposed part of the pteygoid and the ventral surface of the ectopterygoid (Jones et al., 2009, figure 30 and 32). The pterygoideus atypicus originates on a tendon attachment on the dorsal surface of the palate (Jones et al., 2009, p. 24). In Alligator, the pterygoideus muscles are subdivided into the pterygoideus dorsalis and pterygoideus ventralis. The pterygoideus dorsalis originates along the dorsal surface of the pterygoid, ectopterygoid, and palatine as well as the ventral surface of the interorbital septum (Holliday and Witmer, 2007, table 3) and pterygoideus ventralis orginates on the posteromedial and posterolateral edge of the pteygoid. The pterygoideus musculature in Libonectes is treated as a single unit. The pterygoid in plesiosaurs forms a major component of the flat palate (see Maisch and Rücklin, 2000; Sato, 2002; Smith, 2007; O' Keefe, 2004). On the other hand, there is no pterygoid process as in Sphenodon, and no posterior flange as in Alligator. Instead, in plesiosaurs, the pterygoid wraps laterally composing a large portion of the medial wall of the supratemporal fenestra. This condition is an indicator of the poor role of the $\mathrm{mPT}$. 
Thus, the lack of any evident structures to accommodate the $\mathrm{mPT}$, contrarily to the phylogenetic brackets, we consider that its origin is on the ventral portion of the pterygoid and ectopterygoid. This incipient structure is generally described as the pterygoid-ectopterygoid boss and possibly extending to the lateral wall of the pterygoid (Figure 6). The lateral wall of the pterygoid is smooth and medially depressed, and the ventral boss is rugose. The small area of origin agrees with its relatively small importance on the jaw adduction (see discussion for further details). Level I inference.

Insertion - In Sphenodon, the insertion of the pterygoideus typicus is on the medial surface of the articular, the dorsal surface of the articular (posterior to the glenoid), and the ventrolateral surface of the angular and dentary. In lateral view, the insertion extends anteriorly to the same point as the coronoid eminence (Jones et al., 2009, figure 25-1,2 and 3 ; p. 23). The pterygoideus atypicus inserts along a thin strip continuing anteroposteriorly beneath the insertion of the pseudotemporalis profundus, and on a small circular area on the shelf formed by the ventral wall of the adductor fossa, roughly halfway between the glenoid and the apex of the coronoid eminence; however, there is some individual variation (Jones et al., 2009, p. 25, figure 25-2). In Alligator, the pterygoideus dorsalis inserts on the posteromedial surface of the angular and articular; and the pterygoideus ventralis inserts on the posteroventral edge of angular and the posterolateral surface of the angular and surangular. In Libonectes, this muscle inserted on the ventral border of the angular between the coronoid eminence apex and the posterior region of the glenoid (Figure 7). Level I inference.

Musculus depressor mandibulae (mDM): Origin - In Sphenodon,the depressor mandibulae originates on the posterodorsal wall of the squamosal, extending ventrally until the opisthotic (Jones et al., 2009, p. 29). In many crocodilians, the depressor mandibulae originates from the posterior region of the squamosal and quadrate (Endo et al., 2002). Libonectes has a large portion of the right squamosal and quadrate preserved, but this taxon might have extended even further dorsally as in Callawayasaurus (Welles, 1962). The origin of the depressor mandibulae in Libonectes was located on the posterior wall of the quadrate, which bears extensive muscle scars and a subtle depression along its dorsoventral extention (Figure 6). The squamosal is exposed laterally in Libonectes, although it wraps around the posterior side of the skull in Callwayasaurus. Therefore both the quad- rate (ventrally) and the squamosal (dorsally) served for insertion of the depressor mandibulae. Level I inference.

Insertion - In Sphenodon (Jones et al., 2009, figure 25-2), Caiman (Van Drongelen and Dullemeijer, 1982, figure 4), and turtles (Lutz et al., 1996, table 2.1 and see also Werneburg, 2011) the $\mathrm{mDM}$ inserts on the posterior-most surface of the articular. The retroarticular process is not preserved for Libonectes. In Callawaysaurus it is not very long (Table 2), and was probably similar in Libonectes. Therefore, this conservative muscle likely inserted on the posterior part of the articular in Libonectes (Figure 7). Level I inference.

\section{Finite-element Analyses}

Below we present the results of finite-element analyses performed on a base model of Libonectes morgani and three morphological variants.

Base Model (BM): The base model of Libonectes under the defined loading conditions exhibited the highest stresses for strain energy density of $\sim 1 \times 10^{4} \mathrm{~Pa}$ and von Mises stress of $\sim 7 \times 10^{7} \mathrm{~Pa}$. The regions of highest stress are located in the anterior portion of the parietal crest, the posterior portion of the premaxillary dorsal ramus, the anterior portion of the jugal where it contacts the orbit, the posterior portion of the ectopterygoid that contacts the supratemporal fenestra, the medial wall of the squamosal, and the posterior portion of the pterygoid (Figure 8). Areas with lower ( $\left.\sim 5 \times 10^{7} \mathrm{~Pa}\right)$ stress regimes include the postorbital, the posterior portion of the parietal near the suture with the squamosal, the posterior portion of the jugal, and the pterygoid lateral wall anterior to the slope along the mediolateral axis of the skull.

To test the hypothesis of muscular trade-off of the $\mathrm{mAME}+\mathrm{mPST}$ and $\mathrm{mPT}$, we simulated two distinct loading conditions: (1) LC1, with no adductor mandibulae externus (mAME) action and scaled $\mathrm{MPT}$ forces (the force produced by the $\mathrm{MPT}$ is scaled to the same area of the mAMES+mPST); (2) LC2, with no MPT and normal mAME+mPST.

For LC1, the resulting von Mises stresses (10 $\times 10^{7} \mathrm{~Pa}$ maximum range) accumulated on the ventral portion of the dorsal ramus of the premaxilla, the anterior portion of the jugal where it contacts the orbit, posterior portion of the pterygoid (with stress concentrations shifting medially compared with normal loadings), the postorbital, and the ventral portion of the medial wall of the squamosal (Figure 9). The posterior portion of the pterygoid and the anterior portion of the jugal where it contacts the orbit have highest von Mises stresses. 

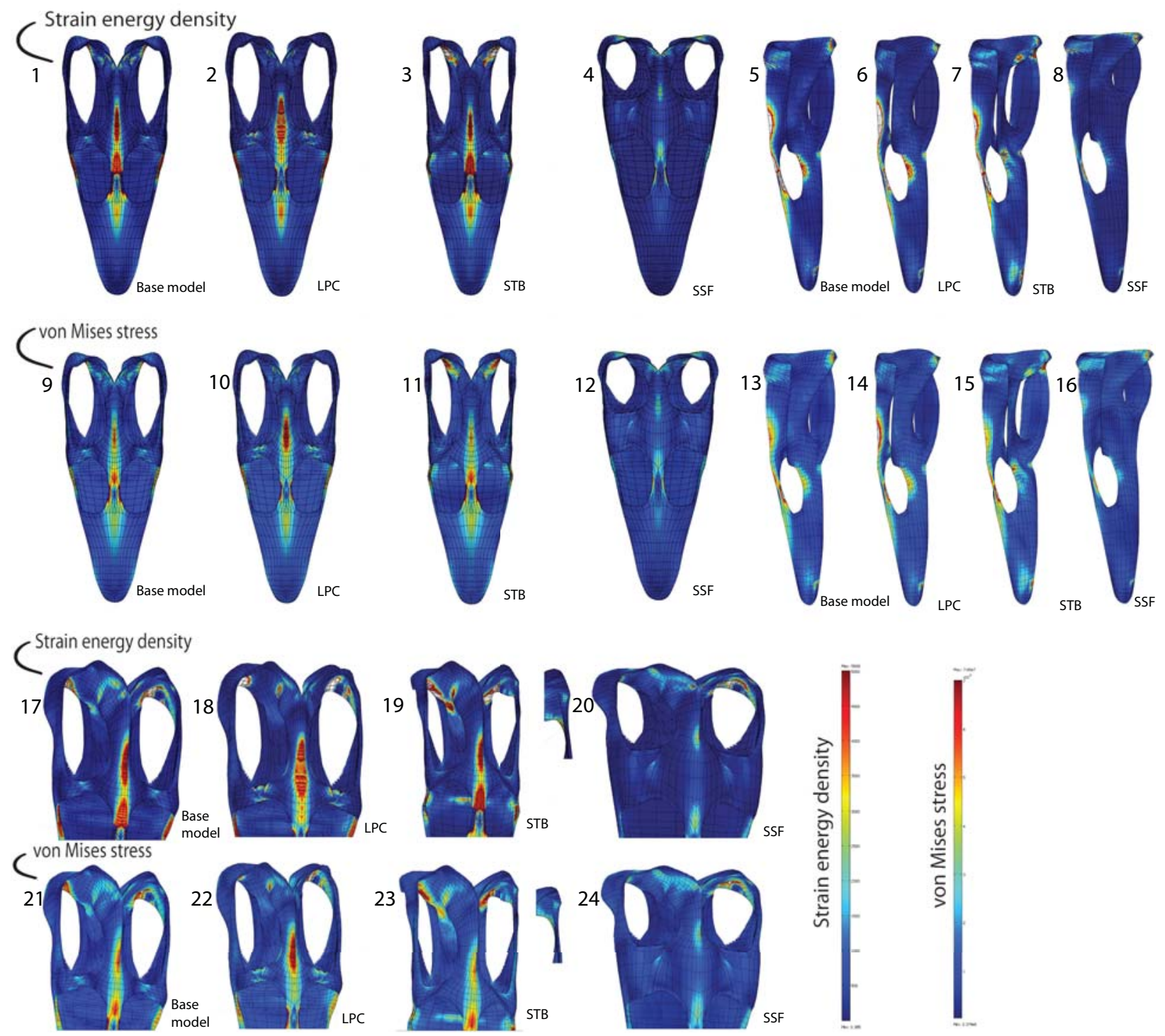

FIGURE 8. Finite-element models results. STB - shallow temporal bar variant model; LPC - low parietal crest variant model; SSF - small supratemporal fenestra variant model. Strain energy density, results in dorsal view: 1 Base model, 2 low parietal crest model, 3 shallow temporal bar model, 4 small supratemporal fenestra model. In lateral view: 5 Base model, 6 low parietal crest model, 7 shallow temporal bar model, 8 small supratemporal fenestra model. Von Mises stresses, results in dorsal view: 9 Base model, 10 low parietal crest model, 11 shallow temporal bar model, 12 small supratemporal fenestra model. In lateral view: 13 Base model, 14 low parietal crest model, 15 shallow temporal bar model, 16 small supratemporal fenestra model. Strain energy density, results in anterodorsal view:n17 Base model, 18 low parietal crest model, 19 shallow temporal bar model, 20 small supratemporal fenestra model. Von Mises stresses, results in anterodorsal view: 21 Base model, 22 low parietal crest model, 23 shallow temporal bar model, 24 small supratemporal fenestra model.

For LC2 (Figure 9), von Mises stresses (6 to $8 \times 10^{7}$ $\mathrm{Pa}$ ) concentrate primarily on the paraoccipital process, the posteriormost portion of the dorsal ramus of the premaxilla, and the postorbital, and secondarily on the anterior portion of the parietal crest. The total area of von Mises stresses higher than $8 \times 10^{7} \mathrm{~Pa}$ is larger in LC1 than LC2 (Figure 9).
These two tests are comparable because they have the same total force involved.

Variant models: The SSF variant has no relevant high stresses (i.e., vast majority of the skull $<3 \times 10^{7}$ $\mathrm{Pa}$ ). Analysis of the other modified models reveals five areas where stresses are high $\left(>6 \times 10^{7} \mathrm{~Pa}\right)$ : (1) the sagittal plane of the skull from the dorsal ramus of the premaxilla extending posteriorly to the body 
1

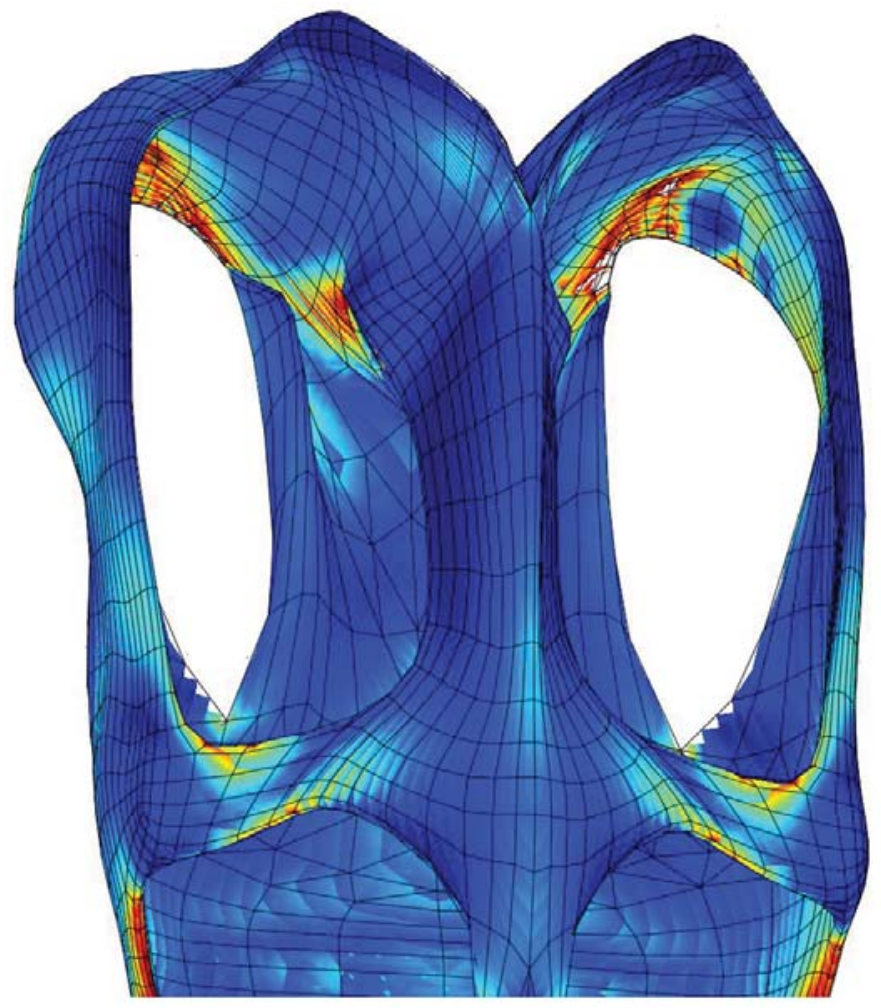

2

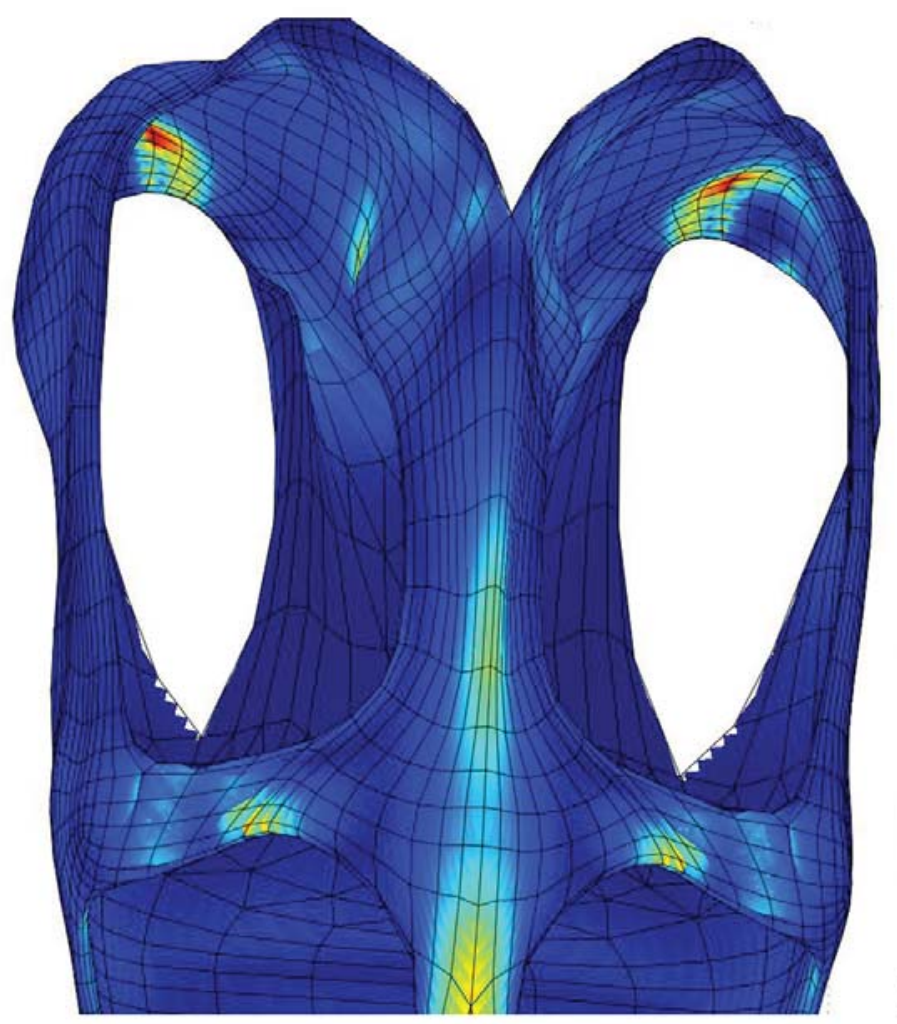

Max: $1.00 e 8$

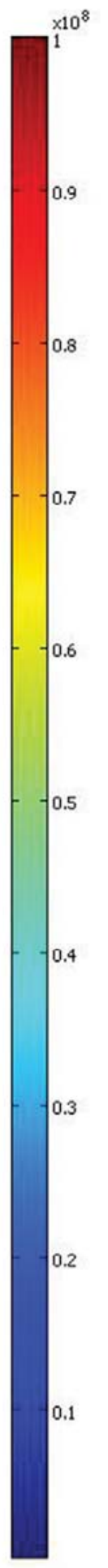

Min: $3.49 e 5$

FIGURE 9. Libonectes morgani base model with posterior part of the skull viewed anterodorsally. 1 Results for the model with scaled forces at pterygoid (LC1). 2 Results for the model with no pterygoid (LC2). 
of the parietal, (2) the postorbital, (3) the palate between the pterygoid and the squamosal, (4) the anterior part of the jugal where it contacts the orbit, and (5) the medial wall of the temporal bar.

The results for strain energy density scale with those for von Mises stress. Along the sagittal plane, both the BM and STB variants perform equally well (i.e., stresses concentrate in the same areas and to the same extent). The LPC variant displays larger areas of high stress, especially along the anteroposterior extension of the parietal. The STB model displays highly stressed regions posterior to the lateral wall of the pterygoid above a von Mises stress of $7 \times 10^{7} \mathrm{~Pa}$ and strain energy density of $5 \times 10^{3} \mathrm{~Pa}$. In the postorbital, the $\mathrm{BM}$ and the LPC variant display stressed areas above a von Mises stress $4,5 \times 10^{7} \mathrm{~Pa}$ and a strain energy density of $3,5 \times 10^{3} \mathrm{~Pa}$. For the anterior part of the jugal where it contacts the orbit, all variants perform similarly, with highest values around $6 \times 10^{7} \mathrm{~Pa}$ von Mises stress. The model that has the lowest von Mises stresses and strain energy density is the STB variant in the medial wall of the temporal bar. This is because the area of attachment for the mAMES is much reduced, thus the total force applied also reduces. Both the BM and LPC variants perform similarly in terms of exhibited von Mises stress and strain energy density, but only the LPC model performed slightly worse than the BM with a larger area of strain energy density above $5 \times 10^{3} \mathrm{~Pa}$.

\section{DISCUSSION}

\section{Laser Scans versus CT Scans for FEA}

Laser scanning has been used previously to generate finite-element meshes in biological systems (Tzurkov et al., 2009, p. 98) however, as with using CT data, these are large datasets that are difficult to work with. Because of their large size, these models require optimized software and hardware. Additionally, they may be difficult to process into meshes suitable for FEA. Most recent studies using FEA employ models based on data obtained using CT data (e.g., Rayfield, 2005; Wroe, 2007; Tseng, 2009; Arbour and Snively, 2009; or Young et al., 2012). CT-derived models theoretically allow details of bone internal structure (Rayfield, 2007) to be captured; however, much of this detail is lost when converting the volumetric CT data to a model, and is further degraded when applying material proprieties to the model (Richmond et al., 2005). The quality of CT data from fossils is variable and usually requires manual or semi-auto- mated segmentation, achieved by tracing the external surfaces of the bones and larger structures within the bone. Few studies (e.g., Moazen et al., 2009) have attempted to incorporate details such as sutures (Rayfield, 2007 and references therein). Furthermore, most published studies employ surface models of the fossils (see Rayfield, 2005; Wroe, 2007; Tseng, 2009; Arbour and Snively, 2009; Jasinoski et al., 2010; Young et al., 2012), and internal details such as bone trabeculae or sinuses are ingnored and treated as solid bone. Considering this, 3D laser scanning data provides accurate models which are appropriate for many biomechanical analyses. A simple iso-surface extraction from CT data could provide a starting point, but the cost of data acquisition favors the use of laser scanning,

The technique in this paper employs one more level of simplification beyond the laser scanning stage, by using the scans as a guide for the creation of simplified NURBS or polygonal models. This simplicity allows the relatively easy creation of multiple models with different attributes that can be compared to assess sensitivity to changes in morphology or prescribed loading conditions. These simplified models allow us to alter the morphology in various ways, creating a series of models for comparative purposes. Additionally, a number of new 3D software programs include features to interactively create simplified 3D models from highpolygon-count data and allow a high degree of user control (Silo ${ }^{\circ}$; Topogun ${ }^{\circledR}$ ); however, these programs currently do not perform well with the extremely large polygon models created by laser scanning or by isosurface extraction methods from CT data. Programs such as Rapidform ${ }^{\circledR}$ allow simplified surface creation from high-polygon-count models, but do not always perform well with complex organic shapes and are optimized for reverse engineering of mechanical structures. Development of algorithms for automated methods of surface fitting and creation of NURBS surfaces is the subject of active research (e.g., Krishnamurthy and Levoy, 1996) and should simplify this task in the future.

\section{Functional Muscular Trade-off in the Adductor Chamber Muscles}

We argue here that the MAME and MPST played a more significant role in jaw adduction versus the MPT in Libonectes, and by extension in other sauropterygians having similar cranial construction. This conjecture is supported by the fact that as the supratemporal fenestra is enlarged, the 
sagittal crest is higher in elasmosaurs relative to other diapsids (e.g., Sphenodon and Alligator), and the area of attachment for the pterygoideus is reduced in all eosauropterygians as a result of the weakened pterygoideus flange (Rieppel, 1995, 2001, 2002). Crocodilians have a large pterygoideus relative to their adductor mandibulae externus musculature (mAME), (e.g., Schumacher, 1973). In crocodilians, the importance of the pterygoideus is illustrated by the long, broad, and posteriorly-oriented pterygoid flange, and in Alligator, the pterygoideus musculature weight is double that of the mAME (Busbey, 1989). In the case of squamates, a similar but less extreme case occurs in which some taxa have developed a large pterygoid flange to support the increased pterygoideus mass when compared to the mAME musculature. For example, both Ctenosaura and Pogona have strongly developed ventrally-descending pterygoid flanges (Oelrich, 1956 ; Banzato et al., 2012). In Ctenosaura, the dry muscle mass for the pterygoideus is $7.6 \mathrm{~g}$ and $3.2 \mathrm{~g}$ for the mAME, i.e., $42 \%$ ratio (Smith, 1982). More impressively, in Pogona the muscle mass for the pterygoideus is $1487 \mathrm{~g}$ versus $1650 \mathrm{~g}$ for the mAME, i.e., $110 \%$ ratio (Schaerlaeken et al., 2008). In contrast, squamates with a poorly developed pterygoid flange have a larger mAME musculature relative to the pterygoideus (for Gekko gekko see Smith, 1982 and Schaerlaeken et al., 2008, for Varanus komodoensis see Moreno et al., 2008, for Varanus exanthematicus see Smith, 1982, and for Tiliqua and Corucia see Schaerlaeken et al., 2008). Turtles are not a good analogue in this respect because because the pterygoideus and mAME muscles act synergistically to lift the jaw (e.g., Schumacher, 1973, Lemell et al., 2000).

Further support for the muscular trade-off hypothesis comes from experiments LC1 and LC2. The BM performs better in LC2 $\left(5 \times 10^{7} \mathrm{~Pa}\right.$ maximum von Mises stress) than in LC1 $\left(10 \times 10^{7} \mathrm{~Pa}\right.$ maximum von Mises stress located posterior to the pterygoid lateral wall). This result suggests that the skull is not well-suited to accommodate high stresses in the region of the pterygoideus origin, but can accommodate high stresses in the parietal region. Therefore, we argue that the pterygoid boss is no more than a remnant of the strong flange seen in non-eosauropterygian diapsids, and that the pterygoideus muscles play a lesser role in adduction. Thus, characters of the adductor chamber region used in previous phylogentic analyses (O'Keefe, 2001; Großmann, 2007; Smith, 2007;
Ketchum and Benson, 2010) have significant biomechanical meaning.

\section{Supratemporal Fenestra Length and Parietal Crest Height}

The size of the supratemporal fenestra relative to the orbit has been used as a phylogenetically useful character by some authors (Bardet et al., 1999; Großmann, 2007). Assuming that the skull to orbit length ratio is relatively constant (Seeleyosaurus: $\sim 20 \%$, Muraenosaurus: $\sim 16 \%$, Libonectes: $\sim 22 \%$, Callawayasaurus: $\sim 17 \%$ ), the length of the temporal fenestra relative to the length of the skull has increased from the plesiomorphic diapsid condition (Table 3). From a biomechanical point of view, a larger temporal fenestra does not create increased stresses in the skull (see Figure 8). However, a larger temporal fenestra provides more room for the insertion of the adductor chamber musculature (mAMEM, mAMEP and MPST) and thus provides increased force (Endo et al., 2002, p. 211). A large temporal fenestra emphasizes the role of the pseudotemporalis and adductor mandibulae externus musculature during jaw adduction in Libonectes. The larger fenestra is accompanied by an increased height of the parietal relative to the height of the adductor chamber (see table 2) in Libonectes and Calawayasaurus, as well as the python, all of which have high parietal crests relative to the height of the adductor chamber. These proportionally higher parietals reflect the increase in area for insertion of the pseudotemporalis and adductor mandibulae externus and results in an increased mechanical performance (Figure 8).

In Gavialis, an extant longirostrine crocodilian, the enlargement of the supratemporal fenestra relative to its brevirostrine relatives also leads to an increasing role of the pseudotemporalis in jaw adduction (Endo et al., 2002). The adductor mandibulae muscles are also extremely important for holding the prey in Caiman crocodylus (Cleuren et al., 1995, table 2).

\section{Tall Temporal Bar}

A dorsoventrally short temporal bar is the plesiomorphic condition in Nothosaurus, Rhomaleosaurus and other more basal eosauropterygians. Our results show that on the medial wall of the temporal bar, the STB variant has lower stress values compared to other models due to the small area for mAMES origin. On the other hand, the STB variant exhibits high stress in the area near the squamosal and pterygoid. This implies that a tall temporal bar 
TABLE 3. Morphometric data of different skull measurements in various eosauropterygians, and extant phylogenetically-relevant taxa used for comparisons and contextualization.

\begin{tabular}{|c|c|c|c|c|c|c|c|}
\hline $\begin{array}{l}\text { Higher-rank } \\
\text { clade }\end{array}$ & Taxon & Specimen & Data Source & 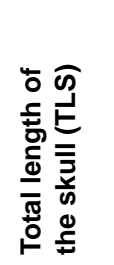 & 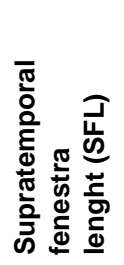 & 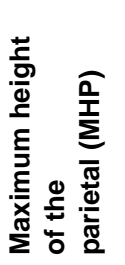 & 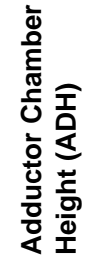 \\
\hline Sauropterygia & Libonectes morgani & SMUSMP 69120 & Measured with ruler & 45 & 17 & 8.5 & 19 \\
\hline Sauropterygia & $\begin{array}{l}\text { Callawayasaurus } \\
\text { columbensis }\end{array}$ & UCMP 38349 & O'Keefe 2001 & 15.8 & 5.8 & 2.9 & 4.56 \\
\hline Sauropterygia & $\begin{array}{l}\text { Rhomaleosaurus } \\
\text { zetlandicus }\end{array}$ & YORYM G503 & Taylor 1992 & 91.1 & 27.23 & 4.4 & 17.3 \\
\hline Sauropterygia & $\begin{array}{l}\text { Nothosaurus } \\
\text { winterswijktensis }\end{array}$ & $\begin{array}{l}\text { NMNHL St 445530, } \\
\text { NMNHL St } 445913\end{array}$ & $\begin{array}{l}\text { Albers and Rieppel } \\
2003\end{array}$ & 131.8 & 46.7 & $?$ & $?$ \\
\hline Sauropterygia & Nothosaurus haasi & HUJ-Pal 2250 & Rieppel et al 1999 & 119.2 & 38.8 & 4.8 & 13.8 \\
\hline Sauropterygia & $\begin{array}{l}\text { Placochelys } \\
\text { placodonta }\end{array}$ & FAFI Ob/2323/Vt.3 & Rieppel 2001 & 156.8 & 74.4 & 14.9 & 47.8 \\
\hline Sauropterygia & Cyamodus rostratus & UMO BT 748 & Rieppel 2001 & 118.6 & 57.9 & 14.31 & 64.48 \\
\hline Sauropterygia & Henodus chelyops & Specimen I and II & Rieppel 2001 & 145.6 & 62.5 & $?$ & 50.2 \\
\hline Sauropterygia & Macroplacus raeticus & BSP 1967 I 324 & Rieppel 2001 & 191.1 & 96.9 & 24.6 & 69.8 \\
\hline Sauropterygia & $\begin{array}{l}\text { Protenodontosaurus } \\
\text { italicus }\end{array}$ & MFSN 1819GP & Rieppel 2001 & 156 & 63.6 & 15.5 & 74.5 \\
\hline Crocodilyformes & Alligator mississipensis & SMU Uncatalogued & $\begin{array}{l}\text { Measured with ruler } \\
\text { and calliper }\end{array}$ & 450 & 28.08 & 13.69 & 133.88 \\
\hline Chelonia & Chelydra serpentina & SMU R-160 & Measured & 106.83 & 64.32 & 13.82 & 39.38 \\
\hline Chelonia & Testudo sp. & SMU Uncatalogued & Measured from cast & 120.98 & 66.13 & 14.73 & 54.39 \\
\hline Chelonia & Chelonia mydas & SMU Uncatalogued & Measured & 205.65 & 54.48 & 38.82 & 95.81 \\
\hline Chelonia & Lepidochelys olivacea & SMU Uncatalogued & Measured from cast & 157.6 & 37.58 & 29.55 & 69.44 \\
\hline Varanidae & Varanus & SMU Uncatalogued & $\begin{array}{l}\text { Measured from cast } \\
\text { with ruler and calliper }\end{array}$ & 226 & 49.34 & 14.06 & 63.85 \\
\hline Rhyncocephalia & Sphenodon punctatus & SMU Uncatalogued & Measured from cast & 63.96 & 21.13 & 7.04 & 27.52 \\
\hline Serpentes & Python & SMU Uncatalogued & Measured & 134.52 & 63.52 & 16.92 & 28.93 \\
\hline Lacertidae & Cyclura cornuta & SMU Uncatalogued & Measured from cast & 132.39 & 38.24 & 21.22 & 57.5 \\
\hline Mosasauria & Tylosaurus & SMU Uncatalogued & $\begin{array}{l}\text { Measured from cast } \\
\text { with ruler }\end{array}$ & 150 & 33 & 8 & 33 \\
\hline Mosasauria & Platecarpus & SMU Uncatalogued & $\begin{array}{l}\text { Measured from cast } \\
\text { with ruler and calliper }\end{array}$ & 370 & 95.86 & 19.48 & 90.69 \\
\hline
\end{tabular}

provides structural support to balance quadrate reaction forces and increases the area of origin for the adductor mandibulae externus superficialis (Figure 8). Thus, the tall temporal bar in Libonectes may play a complex role in structural support of the skull or increasing the area for attachment of the adductor mandibulae externus superficialis, or some combination of the two.

\section{Dual Adductor System}

Olson (1961) categorized the jaw adductor function of several tetrapod taxa into static pres- sure and kinetic inertial modes. A static pressure model is one in which the jaw action is designed for speed during adduction, providing little force in small gapes and kinetic inertial model where jaw action is optimized for low angle gapes (e.g., Alligator mississipiensis), with developed pterygoideus musculature. The kinetic inertial model favors jaw closure velocity over bite force and is exemplified by Gavialis, a fish-eater (i.e., fast jaw adduction) in which the adductor mandibulae musculature is well-developed, and the pterygoideus is relatively unimportant (Endo et al., 2002). 
A dual adductor system is a combination of the kinetic inertial and static pressure models. Taylor (1992) first proposed the dual adductor system for rhomaleosaurid plesiosaurs and as the general mechanism of jaw closure in plesiosaurs, including elasmosaurids. The evidence for a dual adductor system relies upon the attachment and force production of the pterygoideus in relation to the force produced by the temporal adductor muscles. The origin of the pterygoideus on an undeveloped pterygoid flange in most plesiosaurs is not consistent with use as a primary jaw aductor. Thus we conclude that the dual adductor system of Taylor (1992) is not consistent with the results obtained by osteological, myological, and finite element analyses presented here (Figures 3-8) and indicates reduced importance of the pterygoideus musculature in plesiosaurs. We suggest a kinetic inertial model (sensu Olson, 1961) was used exclusively in Libonectes and by extension, other eosauropterygians with equivalent cranial construction. Rapid, rather than forceful, adduction by the adductor mandibulae externus, pseudotemporalis, and adductor mandibulae posterior is consistent with a prey preference of teleost fishes for elasmosaurids, as well as cephalopods for other plesiosaurians, as previously reported (Cicimurri and Everhart (2001).

\section{CONCLUSIONS}

To quantify the relative roles of osseous morphology and distribution of forces produced by jaw muscles, we presented descriptions of osteology, arthrology, and mycology for Libonectes and performed FEA simulations to test four hypotheses.

Across sauropterygian evolution, morphological changes seen in the adductor chamber, such as the enlargement of the parietal crest and length of the supratemporal fenestra, functioned to accommodate increased mass of the jaw adductor muscles, without reduction of the skull's mechanical performance. Relatively reduced contribution of the force produced by the pterygoideus indicates a minimal role in jaw adduction. Together, these data do not support the hypothesis of a dual adductor system in plesiosaurs. Hypothesis I is not falsified.

Enlarging the supratemporal fenestra decreases skull mechanical performance in all the models tested. Therefore, the selective pressure for supratemporal lengthening relative to the skull is not structural, but instead meant to accommodate larger adductor musculature. Therefore, the reasons for a large supratemporal fenestra are strictly myological. Hypothesis II is not falsified.

The enlargement of the supratemporal fenestra results in the following regions of highest stress: the anterior portion of the parietal crest, the posterior portion of the premaxillary dorsal ramus, the anterior portion of the jugal where it contacts the orbit, the posterior portion of the ectopterygoid that contacts the supratemporal fenestra, the medial wall of the squamosal, and the posterior portion of the pterygoid. In all the models tested, enlarging the height of the temporal bar increases skull mechanical performance, namely in the pterygoid/ squamosal region. Moreover, a taller temporal bar provides larger area of attachment for the adductor mandibulae externus superficialis. Thus, the functional reasons for a high temporal bar are both mechanical and myological. Hypothesis III is not falsified.

Augmentation of the height of the temporal bar leads to stress reduction in the posterior wall of the pterygoid. Augmenting the height of the parietal crest increases skull mechanical performance in all the models tested. Mechanical performance is greater with a high parietal, and the area for muscle attachment also increases. Functional reasons for such changes are both structural and myological. Increasing the height of the parietal crest leads to a decrease in stress in this region, as well as on the postorbital. Hypothesis IV is not falsified.

\section{ACKNOWLEDGMENTS}

We thank D. Winkler, L.L. Jacobs and the other participants in the Biomechanics Seminar for useful discussions. We thank one anonymous reviewer and $\mathrm{N}$. Bardet for reviewing the manuscript and providing insightful comments that greatly improved this contribution. We also thank $\mathrm{S}$. Myers for comments on a previous version of this paper.

\section{REFERENCES}

Alexander, R.M. 1968. Animal Mechanics. Sidgwick \& Jackson, London, UK.

Antón, S.C. 1999. Macaque masseter muscle: internal architecture, fiber length and cross-sectional area. International Journal of Primatology, 20:441-462.

Antón, S.C. 2000. Macaque pterygoid muscles: internal architecture, fiber length, and cross-sectional area. International Journal of Primatology, 21:131-156.

Arbour, V.M. and Snively, E. 2009. Finite element analyses of ankylosaurid dinosaur tail club impacts. The Anatomical Record, 292:1412-1426. 
Banzato, T., Selleri, P., Veladiano, I.A., Martin, A., Zanetti, E., and Zotti, A. 2012. Comparative evaluation of the cadaveric, radiographic and computed tomographic anatomy of the heads of green iguana (Iguana iguana), common tegu (Tupinambis merianae) and bearded dragon (Pogona vitticeps). BMC Veterinary Research, 8:53.

Bardet, N., Godefroit, P., and Sciau, J. 1999. A new elasmosaurid from the Lower Jurassic of Southern France. Palaeontology, 42: 927-952.

Bayraktar, H.H., Morgan, E.F., Niebur, G.L., Morris, G.E., Wong, E.K., and Keaveny, T.M. 2004. Comparison of the elastic and yield properties of human femoral trabecular and cortical bone tissue. Journal of Biomechanics, 37:27-35.

Benson, R.B.J., Evans, M., and Druckenmiller, P.S. 2012. High Diversity, Low Disparity and Small Body Size in Plesiosaurs (Reptilia, Sauropterygia) from the Triassic-Jurassic Boundary. PLOS ONE, 7(3):e31838. doi:10.1371/journal.pone.0031838.

Bryant, H.N. and Russell, A.P. 1992. The role of phylogenetic analysis in the inference of unpreserved attributes of extinct taxa. Philosophical Transactions: Biological Sciences, 337:405-418.

Busbey, A.B. 1989. Form and function of the feeding apparatus of Alligator mississippiensis. Journal of Morphology, 202:99-127.

Caldwell, M. 1996. Ichthyosauria: a preliminary phylogenetic analysis of diapsid affinities. Neues Jahrbuch für Geologie und Paläontologie Abhandlungen, 200:361-386.

Carlson, F.R. and Wilkie, D.R. 1974. Muscle physiology. Prentice-Hall, Englewood Cliffs, New Jersey.

Carpenter, K. 1997. Comparative cranial anatomy of two North American cretaceous plesiosaurs, p. 191-216. In Callaway, J.M. and Nicholls, E.L. (eds.), Ancient Marine Reptiles. Academic Press, San Diego.

Carrano, M.T. and Hutchinson, J.R. 2002. Pelvic and Hindlimb Musculature of Tyrannosaurus rex (Dinosauria: Theropoda). Journal of Morphology, 253:207228.

Cicimurri, D.J. and Everhart, M.J. 2001. An elasmosaur with stomach contents and gastroliths from the Pierre Shale (Late Cretaceous) of Kansas. Transactions of the Kansas Academy of Science, 104:129-143

Cleuren, J., Aerts, P., and de Vree, F. 1995. Bite and joint force analysis in Caiman crocodylus. Belgian Journal of Zoology, 125:79-94.

Currey, J.D. 1988. The effect of porosity and mineral content on the Young's modulus of elasticity of compact bone. Journal of Biomechanics, 21:131-139.

Curtis, N., Witzel, U., Fitton, L., O'Higgins, P., and Fagan, M. 2011. The mechanical significance of the temporal fasciae in Macaca fascicularis: an investigation using finite element analysis. The Anatomical Record, 294:1178-1190.
Curtis, N., Jones, M.E.H., Evans, S.E., Shi, J., O'Higgins. P., and Fagan, M.J. 2010. Predicting muscle activation patterns from motion and anatomy: modelling the skull of Sphenodon (Diapsida: Rhynchocephalia). Journal of the Royal Society Interface, 7:153-160.

Daegling, D.J. and Hylander, W.L. 2000. Experimental observation, theoretical models, and biomechanical inference in the study of mandibular form. American Journal of Physical Anthropology, 112: 541-551.

Daniel, W.J.T. and McHenry, C.R. 2001. Bite force to skull stress correlation: modelling the skull of Alligator mississippiensis, p. 135-143. In Seebacher, F. and Franklin, C.E. (eds.), Crocodilian Biology and Evolution. Surrey Beatty and Sons, New South Wales, Australia.

de Braga, M. and Rieppel, O. 1997. Reptile phylogeny and the interrelationships of turtles. Zoological Journal of the Linnean Society, 120:281-354.

Dechow, P.C., Nail, G.A., Schwartz-Dabney, C.L. and Ashman R.B. 1993. Elastic properties of human supraorbital and mandibular bone. American Journal Physical Anthropology 90:29-306.

Desojo, J.B. and Vizcaino, S.F. 2009. Jaw biomechanics in the South American aetosaur Neoaetosauroides engaeus. Palaontologische Zeitschrift, 83: 499-510.

Druckenmiller, P.S. and Russell, A.P. 2008. Skeletal anatomy of an exceptionally complete specimen of a new genus of plesiosaur from the Early Cretaceous (Early Albian) of northeastern Alberta, Canada. Palaeontographica Abteilung A, 283:1-33.

Endo, H., Aoki, R., Taru, H., Kimura, J., Sasaki, M., Yamamoto, M., Arishima, K., and Hayashi, Y. 2002. Comparative functional morphology of the masticatory apparatus in the long-snouted Crocodiles. Anatomy Histolology and Embryology, 31:206-213.

Erickson, G.M., Catanese, J., and Keaveny, T.M. 2002. Evolution of the biomechanical material properties of the femur. The Anatomical Record, 268:115-124.

Frazzetta, T.H. 1962. A functional consideration of cranial kinesis in lizards. Journal of Morphology, 3: 287319.

Gasparini, Z., Bardet N., and Iturralde-Vinent M. 2002. A new cryptoclidid Plesiosaur from the Oxfordian (Late Jurassic) of Cuba. Geobios, 35:201-211.

Großmann, F. 2007. The taxonomy and phylogenetic position of the plesiosauroidea from the lower Jurassic Posidonia Shale of South-West Germany. Palaeontology 50:545-564.

Haas, G. 1960. The trigeminus muscles of the lizards Xenosaurus grandis and Shinisaurus crocodilurus. American Museum Novitates, 2017:1-54.

Haas, G. 1973. Muscles of the jaws and associated structures in the Rhynchocephalia and Squamata, p. 285-490. In Gans, C. and Parsons, T.S. (eds.), Biology of the Reptilia, 4. Academic Press, London.

Herring, S.W. and Tseng, S. 2000. Strain in the braincase and its sutures during function. American Journal of Physical Anthropology, 112:575-593. 
Hieronymus, T.L. 2006. Quantitative microanatomy of jaw muscle attachment in extant diapsids. Journal of Morphology, 267: 954-967.

Holliday, C.M. and Witmer L.M. 2007. Archosaur adductor chamber evolution: integration of musculoskeletal and topological criteria jaw muscle homology. Journal of Morphology, 268: 457-484.

Iordansky, N.N. 1964. The jaw muscles of the crocodiles and some relating structures of the crocodilian skull. Anatomischer Anzeiger, 115:256-280.

Iordansky, N.N. 2000. Jaw muscles of the crocodiles: structure, synonymy, and some implications on homology and functions. Russian Journal of Herpetology, 7:41-50.

Jasinoski, S.C., Rayfield, E.J., and Chinsamy A. 2010. Mechanics of the scarf premaxilla-nasal suture in the snout of Lystrosaurus. Journal of Vertebrate Paleontology, 30:1283-1288.

Jones, M E.H., Curtis N., Fagan M.J., O'Higgins P., and Evans S.E. 2011. Hard tissue anatomy of the cranial joints in Sphenodon (Rhynchocephalia): sutures, kinesis, and skull mechanics. Palaeontologia Electronica 14:17A:92p; palaeo-electronica.org/2011_2/ 251/index.html.

Jones, M.E.H., Curtis, N., O'Higgins, P., Fagan, M., and Evans, S.E. 2009. The head and neck muscles associated with feeding in Sphenodon (Reptilia: Lepidosauria: Rhynchocephalia). Palaeontologia Electronica, 12:1-56.

Ketchum, H.F. and Benson R.B.J. 2010. Global interrelationships of Plesiosauria (Reptilia, Sauropterygia) and the pivotal role of taxon sampling in determining the outcome of phylogenetic analyses. Biological Reviews, 85:361-392.

Krishnamurthy, V. and Levoy, M. 1996. Fitting smooth surfaces to dense polygon meshes. SIGGRAPH '96. New Orleans, LA, USA, 4-9:313-24.

Kupczik, K. 2008. Virtual biomechanics: basic concepts and technical aspects of finite element analysis in vertebrate morphology. Journal of Anthropological Sciences, 86:193-198.

Lakjer, T. 1926. Die Trigeminus-Versorgte Kaumuskulature der Sauropsiden. CA Reitzel, Copenhagen, Denmark.

Lemell, P., Beisser, C.J., and Weisgram, J. 2000. Morphology and function of the feeding apparatus of Pelusios castaneus (Chelonia; Pleurodira). Journal of Morphology, 244:127-135.

Liu, J., Rieppel, O., Jiang, D.-Y., Aitchison, J.C., Motani, R., Zhang, Q.-Y., Zhou, C.-Y., and Sun, Y.-Y. 2011. A new pachypleurosaur (Reptilia: Sauropterygia) from the Lower Middle Triassic of Southwestern China and the phylogenetic relationships of chinese pachypleurosaurs. Journal of Vertebrate Paleontology, 31:292-302.
Lutz, P.L., Musick, J.A., and Wyneken, J. 1996. The biology of sea turtles Volume II. CRC Press: Washington.

Maisch, M.W. and Rücklin, M. 2000. Cranial osteology of the sauropterygian Plesiosaurus brachypterygius from the lower Toarcian of Germany. Palaeontology 43:29-40.

Mateus, O., Polcyn, M.J., Jacobs, L.L., Araújo, R., Schulp, A.S., Marinheiro, J., Pereira, B., and Vineyard, D. in press Cretaceous amniotes from Angola: dinosaurs, pterosaurs, mosasaurs, plesiosaurs, and turtles. Sala de Los Infantes: V Jornadas Internacionales sobre Paleontología de Dinosaurios y su Entorno.

McHenry, C.R., Clausen, P.D., Daniel, W.J.T., Meers, M.B., and Pendharkar, A. 2006. Biomechanics of the rostrum in crocodilians: a comparative analysis using finite-element modeling. The Anatomical Record A, 288A: 827-849.

Moazen, M., Curtis, N., Evans, S.E., O'Higgins, P., and Fagan, M.J. 2008. Combined finite element and multibody dynamics analysis of biting in a Uromastyx hardwickii lizard skull. Journal of Anatomy, 213:499508.

Moazen, M., Curtis, N., O'Higgins, P., Jones, M.E.H., Evans, S.E., and Fagan, M.J. 2009. Assessment of the role of sutures in a lizard skull: a computer modelling study. Proceedings of the Royal Society $B$, 276:39-46

Moreno, K., Wroe, S., Clausen, P., McHenry, C., D'Amore, S.C., Rayfield, E.J., and Cunningham, E., 2008. Cranial performance in the Komodo dragon (Varanus komodoensis) as revealed by high-resolution 3-D finite element analysis. Journal of Anatomy, 212:736-746.

Motani, R. 2009. The Evolution of Marine Reptiles. Evolution: Education and Outreach 2:224235.

Motani, R., Minoura, N., and Ando, T. 1998. Ichthyosaurian relationships illuminated by new primitive skeletons from Japan. Nature, 393:255-257.

Oelrich, T.M. 1956. The Anatomy of the Head of Ctenosaura pectinata (Iguanidae). Miscellaneous Publications, Museum of Zoology, University of Michigan. 94:1-122.

O'Keefe, F.R. 2001. A cladistic analysis and taxonomic revision of the Plesiosauria (Reptilia: Sauropterygia). Acta Zoologica Fennica, 213:1-63.

O'Keefe, F.R. 2004. On the cranial anatomy of the polycotylid plesiosaurs, including new material of Polycotylus latipinnis, Cope, from Alabama. Journal of Vertebrate Paleontology, 24:326-340.

O'Keefe, F.R. and Carrano, M.T. 2005. Correlated trends in the evolution of the plesiosaur locomotor system. Paleobiology, 31:656-675.

Olson, E.C. 1961. Jaw Mechanisms: Rhipidistians, Amphibians, Reptiles. American Zoologist 1: 205215. 
Otero, R.A., Soto-Acuña, S., and Rubilar-Rogers, D. 2012. A postcranial skeleton of an elasmosaurid plesiosaur from the Maastrichtian of central Chile, with comments on the affinities of Late Cretaceous plesiosauroids from the Weddellian Biogeographic Province. Cretaceous Research, 37:89-99.

Rafferty, K.L. and Herring, S.W. 1999. Craniofacial Sutures: morphology, growth, and in vivo masticatory strains. Journal of Morphology, 242:167-179.

Rayfield, E.J. 2005. Using finite-element analysis to investigate suture morphology: a case study using large carnivorous dinosaurs. The Anatomical Record, 283A:349-365.

Rayfield, E.J. 2007. Finite element analysis and understanding the biomechanics and evolution of living and fossil organisms. Annual Review of Earth and Planetary Sciences, 35:541-76.

Rho, J.-Y., Tsui, T.Y., and Pharr, G.M.1997. Elastic properties of human cortical and trabecular lamellar bone measured by nanoindentation. Biomaterials, 18:1325-1330.

Richmond, B.,Wright, B., Grosse, I., Dechow, P., Ross, C., Spencer, M., and Strait, D. 2005 Finite element analysis in functional morphology. The Anatomical Record A, 283:259-274.

Rieppel, O. 1994. Osteology of Simosaurus gaillardoti and the relationships of stem-group sauropterygia. Fieldiana (Geology), 1462:1-85.

Rieppel, O. 1995. The genus Placodus: systematics, morphology, paleobiogeography, and paleobiology. Fieldiana (Geology) n.s., 31:1-44.

Rieppel, O. 2000. Sauropterygia I: Placodontia, Pachypleurosauria, Nothosauria, Piatosauroidea, p.1-134. In Wellnhofer, P. (ed.), Encyclopedia of Palaeoherpetology, Vol. 12A. Pfeil, Munich.

Rieppel, O. 2001. The cranial anatomy of Placochelys placodonta Jaekel, 1902, and a review of the Cyamodontoidea (Reptilia, Placodonta). Fieldiana (Geology,) n.s., 45:1-104.

Rieppel, O. 2002. Feeding mechanics in Triassic stemgroup sauropterygians: the anatomy of a successful invasion of Mesozoic seas. Zoological Journal of the Linnean Society, 135:33-63.

Rieppel, O. and deBraga, M. 1996. Turtles as diapsid reptiles. Nature, 384:453-455.

Riess, J. and Frey, E. 1991. The evolution of underwater flight and the locomotion of plesiosaurs, p. 131-144. In Rayner, J.M.V. and Wootton, R.J. (eds.), Biomechanics in Evolution. Cambridge University Press, Cambridge, UK.

Robinson, J.A. 1975. The locomotion of plesiosaurs. Neues Jahrbuch für Geologie und Paläontologie, Abhabdlungen, 149:286-332.

Sato, T. 2002. Description of plesiosaurs (Reptilia: Sauropterygia) from the Bearpaw Formation (Campanian-Maastrichtian) and a phylogenetic analysis of the Elasmosauridae. Unpublished D. PhD Thesis, University of Calgary, Canada.
Sato T. 2003. Terminonatator ponteixensis, a new elasmosaur (Reptilia: Sauropterygia) from the Upper Cretaceous of Saskatchewan. Journal of Vertebrate Paleontology, 23:89-103.

Sato, T. and Tanabe, K. 1998. Cretaceous plesiosaurs ate ammonites. Nature, 394:629-630.

Sato, T., Hasegawa, Y., and Manabe, M. 2006. A new elasmosaurid plesiosaur from the Upper Cretaceous of Fukushima, Japan. Palaeontology, 49:467-484.

Schaerlaeken V., Herrel A., Aerts P., and Ross, C.F. 2008. The functional significance of the lower temporal bar in Sphenodon punctatus. The Journal of Experimental Biology, 211:3908-3914.

Schumacher, G.H. 1973. The head muscles and hyolaryngeal skeleton of turtles and crocodilians, p. 101200. In Gans, C. and Parsons, T.S. (eds.), Biology of the Reptilia, Volume 4: Morphology D. Academic Press, New York.

Shuler, E.W. 1950. A new elasmosaur from the Eagle Ford Shale of Texas. Fondren Science Series, 1:133.

Smith, K.K. 1982. An electromyographic study of the function of the jaw adducting muscles in Varanus exanthematicus (Varanidae). Journal of Morphology, 173:137-158.

Smith, A.S. 2007. Anatomy and systematic of the Rhomaleosauridae (Sauropterygia: Plesiosauria). Unpublished PhD Thesis, University College Dublin, Republic of Ireland.

Taylor, M.A. 1992. Functional anatomy of the head of the large aquatic predator Rhomaleosaurus zetlandicus (Plesiosauria, Reptilia) from the Toarcian (Lower Jurassic) of Yorkshire,England. Philosophical Transactions of the Royal Society of London B, 335:247280.

Taylor, M.A. and Cruickshank, A.R.I. 1993. Cranial anatomy and functional morphology of Pliosaurus brachyspondylus (Reptilia: Pleasiosauria) from the Upper Jurasic of Westbury, Wilshire. Philosophical Transactions: Biological Sciences, 335:247-280.

Thomason, J.J., Russell, A.P., and Morgeli, M. 1990. Forces of biting, body size, and masticatory muscle tension in the opossum Didelphis virginiana. Canadian Journal of Zoology, 68:318-324.

Tseng Z.J. 2009. Cranial function in a late Miocene Dinocrocuta gigantea (Mammalia: Carnivora) revealed by comparative finite element analysis. Biological Journal of the Linnean Society, 96:51-67.

Tsukrov, I., DeCewb, J.C., Baldwin, K., CampbellMalone, R., and Moore, M.J. 2009. Mechanics of the right whale mandible: full scale testing and finite element analysis. Journal of Experimental Marine Biology and Ecology, 374:93-103.

Tumarkin-Deratzian, A.R., Vann, D.R., and Dodson, P. 2007. Growth and textural ageing in long bones of the American alligator Alligator mississippiensis (Crocodylia: Alligatoridae). Zoological Journal of the Linnean Society, 150:1-39. 
van Drongelen, W. and Dullemeijer, P. 1982. The feeding apparatus of Caiman crocodilus: a functional-morphological study. Anatomischer Anzeiger, 151:337366.

Welles, S.P. 1962. A new species of elasmosaur from the aptian of Colombia and a review of the Cretaceous plesiosaurs. University of California Publications in Geological Sciences, 44:1-96.

Weijs, W.A. and Hillen, B. 1985. Cross-sectional estimated intrinsic strength of the human jaw muscle. Acta morphologica Neerlando-Scandinavica, 23:267274.

Werneburg, I. 2011. The cranial musculature of turtles. Palaeontologia Electronica, 14: 15A:99p; palaeoelectronica.org/2011_2/254/index.html.

Wiffen, J. and Moisley, W.L. 1986. Late Cretaceous reptiles (Families Elasmosauridae and Pliosauridae) from the Mangahouanga Stream,North Island,New Zealand. New Zealand Journal of Geology and Geophysics, 29:205-252.
Witmer, L.M. 1995. The extant phylogenetic bracket and the importance of reconstructing soft tissues in fossils, p. 19-33. In Thomason, J.J. (ed.), Functional Morphology in Vertebrate Paleontology. Cambridge University Press, New York.

Witmer, L.M. 1997. The evolution of the antorbital cavity in archosaurs: a study in soft-tissue reconstruction in the fossil record with an analysis of the function of pneumaticity. Memoirs of the Society of Vertebrate Paleontology. Journal of Vertebrate Paleontology, 17 (supplement to 1):1-73.

Wroe, S. 2007. Cranial mechanics compared in extinct marsupial and extant African lions using a finite-element approach. Journal of Zoology, 274:332-339.

Young, M.T., Rayfield, E.J., Holliday, C.M., Witmer, L.M., Button, D.J., Upchurch, P., and Barrett, P.M. 2012. Cranial biomechanics of Diplodocus (Dinosauria, Sauropoda): testing hypotheses of feeding behavior in an extinct megaherbivore. Naturwissenschaften, 99:637-643 